\title{
What can inactivity (in its various forms) reveal about affective states in non-human animals? A review
}

Article

Accepted Version

Creative Commons: Attribution-Noncommercial-No Derivative Works 4.0

Fureix, C. and Meagher, R. K. (2015) What can inactivity (in its various forms) reveal about affective states in non-human animals? A review. Applied Animal Behaviour Science, 171. pp. 8-24. ISSN 0168-1591 doi:

https://doi.org/10.1016/j.applanim.2015.08.036 Available at https://centaur.reading.ac.uk/68177/

It is advisable to refer to the publisher's version if you intend to cite from the work. See Guidance on citing.

To link to this article DOI: http://dx.doi.org/10.1016/j.applanim.2015.08.036

Publisher: Elsevier

All outputs in CentAUR are protected by Intellectual Property Rights law, including copyright law. Copyright and IPR is retained by the creators or other copyright holders. Terms and conditions for use of this material are defined in the End User Agreement.

www.reading.ac.uk/centaur 
Central Archive at the University of Reading

Reading's research outputs online 
1 What can inactivity (in its various forms) reveal about affective states in non-human 2 animals? A review

3

4 Carole Fureix $^{\mathrm{a}^{*}}$, Rebecca K. Meagher ${ }^{\mathrm{b}}$

5

$6{ }^{\text {a }}$ University of Bristol, School of Veterinary Sciences, Langford House, Langford, Bristol 7 BS40 5DU, United Kingdom

$8{ }^{\mathrm{b}}$ University of British Columbia, Faculty of Land and Food System, 2357 Main Mall, 9 Vancouver, BC V6T 1Z4, Canada

10

11

$12 *$ Corresponding author: carole.fureix@bristol.ac.uk; Tel.: +44 (0)117 331 9221; Fax: +44-

13 0117-928-9582. University of Bristol, School of Veterinary Sciences, Langford House,

14 Langford, Bristol BS40 5DU, UK 


\section{Abstract}

Captive / domestic animals are often described as inactive, with the implicit or explicit implication that this high level of inactivity is a welfare problem. Conversely, not being inactive enough may also indicate or cause poor welfare. In humans, too much inactivity can certainly be associated with either negative or positive affective states. In non-human animals, however, the affective states associated with elevated or suppressed levels of inactivity are still not well understood.

Part of the complexity is due to the fact that there are many different forms of inactivity, each likely associated with very different affective states. This paper has two aims. One is to identify specific forms of inactivity that can be used as indicators of specific affective states in animals. The other is to identify issues that need to be resolved before we could validly use the remaining, not yet validated forms of inactivity as indicators of affective state.

We briefly discuss how inactivity is defined and assessed in the literature, and then how inactivity in its various forms relates to affective (either negative or positive) states in animals, basing our reasoning on linguistic reports of affective states collected from humans displaying inactivity phenotypically similar to that displayed by animals in similar situations, and, when possible, on pharmacological validation. Specific forms of inactivity expressed in response to perceived threats (freezing, tonic immobility, and hiding) appear to be, to date, the best-validated indicators of specific affective states in animals. We also identify a number of specific forms of inactivity likely to reflect either negative (associated with ill-heath, boredom-like, and depression-like conditions), or positive states (e.g. 'sun-basking', postconsummatory inactivity), although further research is warranted before we could use those forms as indicators of the affective states. We further discuss the relationship between increased inactivity and affective states by presenting misleading situations likely to yield wrong conclusions. We conclude that more attention should be paid to inactivity in animal 
40 welfare studies: specific forms of inactivity identified in this paper are, or have the potential 41 to be, useful indicators of affective (welfare) states in animals.

42

43 Key words: inactivity; affective states; indicator; validation; animal welfare; fear 


\section{Introduction}

Captive or domestic animals are often described as inactive, with the implicit (e.g.

Broom, 1988), or explicit implication that this high level of inactivity is a welfare problem (e.g. Zanella et al., 1996; McPhee and Carlstead, 2010). Conversely, not being inactive enough, for instance when external demands require increased efforts to cope with challenges and when severely sleep deprived, may also indicate or cause poor welfare; it can have dramatic adverse consequences for organisms (e.g. Ferrara and De Gennaro, 2001; Maslach et al., 2001). However, the affective states -- our main focus with regards to welfare ${ }^{1}$-associated with these elevated or suppressed levels of inactivity are still not well understood in non-human animals (henceforth 'animals'). This is in part because inactivity has rarely been the focus of behavioural studies and is often considered simply a default state rather than a true 'behaviour' (see e.g. Lima et al., 2005; Levitis et al., 2009).

In humans, too much inactivity can be associated with negative affective states (e.g. psychological distress, Muhsen et al., 2010). In animals, too, inactivity is elevated (and activity decreased) in a variety of situations where welfare is believed to be poor. In an extreme example, monkeys separated from their mothers after birth and raised alone in bare wire cages 'sit in their home cages and stare fixedly into space' (Harlow and Harlow, 1962). Juveniles raised in total isolation until 8 months of age needed as long as 12 to 27 weeks to begin to move at all, when placed with social companions in a room designed to trigger play

63 (Harlow and Harlow, 1962; see Konrad and Bagshaw, 1970 for similar results in cats). Male 64 rats exposed to social defeat become more inactive and less exploratory in novel environments than non-defeated controls (Meerlo et al., 1996a; Meerlo et al., 1996b), while buffalo cows housed in restrictive, high stocking density conditions spend more time in

\footnotetext{
${ }^{1}$ Defining animal welfare is a complex issue, on which not everyone agrees (see e.g. Fraser,'s 3 circles 2008). Measures related to affect have however often been raised as relevant measures for assessing animal welfare; we, following e.g. Duncan, 2005, are principally concerned about this aspect of animal welfare.
} 
67 inactive 'idling' than their counterparts with free access to a large outdoor yard with wallows and grazing opportunities (Tripaldi et al., 2004).

However, inactivity is also elevated in a variety of situations where welfare is selfreported (in humans, e.g. when receiving a gentle massage, Goats, 1994), or believed, to be good. Animals are often inactive when in familiar, safe environments where all immediate needs are met (e.g. Cockram, 2004; Wells, 2005; Nowak, 2006). Meanwhile, frustration of motivations to perform specific activities (deprivation: cf. Dawkins, 1988) tends to increase locomotor activity and to induce stereotypic behaviour, escape attempts and other 'restless' behaviour, thus likely reducing time spent inactive (e.g. migratory birds when caged: Mewaldt and Rose, 1960; laying hens unable to nest: Duncan, 1970; mink blocked from swimming water: Vinke et al., 2005; feed-restricted calves: Vieira et al., 2008, mink: Bildsoe et al., 1991; Hansen and Moller, 2008, horses: Benhajali et al., 2008 and rats: Prescott, 1970). As illustrated in the examples above, the relationship between inactivity and welfare states is far from straightforward. Part of this complexity is due to the fact that inactivity is not a homogeneous category: there are many different forms, expressed in different contexts, and each likely associated with very different affective states. This paper therefore has two aims. One is to identify specific forms of inactivity that can be used as indicators of specific affective states in animals. The second is, for those specific forms of inactivity that are currently not validated as indicators, to identify issues that need to be resolved before we could validly use them as indicators of affective state. It is, however, not our goal here to provide an exhaustive list of specific examples of inactivity being associated with affective states. Instead, we intend to illustrate a rationale and to discuss further research suggestions to achieve a better understanding of the relationship between inactivity and affective states. Neither is our goal to argue that inactivity should be considered as the sole and/or 'gold standard' indicator of affective states in animals, but rather to highlight the potential it has, 
when considered in its specific forms together with contextual information, to help infer animals' affective states. This would be valuable in a wide range of studies, such as those assessing the impact of housing, management, and other procedures on affective states, and to provide practical recommendations for eliciting positive affective states in domestic and captive animals.

In animals, linguistic self-reports on specific affective states, i.e. the 'gold standard' method to capture conscious affective experiences, are obviously not attainable (discussed in e.g. Mendl et al., 2010). Behaviours are thus the only attainable, albeit indirect, measure of putative affective states associated with a given situation. We argue that a partial solution to this problem could be to rely on our own species' experiences (providing face validity and, for some of the states, cf. 3.2.2., etiological validity, e.g. Belzung and Lemoine, 2011). Indeed, acknowledging that we cannot be sure what an inactive dog's, rat's or any other animal's affective experiences are, we can still make reasonable assumptions if animals' behavioural patterns in avoided (hence putatively perceived as aversive) situations are similar to those reported by humans feeling e.g. fearful or depressed in similarly aversive situations (e.g. Mendl et al., 2010). For instance, both a rat exposed to a cat (predator) (Dielenberg and McGregor, 1999), and someone frightened by a stranger entering his/her home late at night (Blanchard et al., 2001), might stay still in a location where s/he is protected behind something. We would argue that the hiding rat is in such a case likely to feel afraid of the perceived threat just as the motionless hiding person does. Following the same rationale, animals' behavioural patterns that are expressed in preferred or positive situations and are similar to those exhibited by humans in similar situations where they report feeling positively-valenced states, are likely to reflect positive affective states. For instance, lying in the sun, which does have a hedonic component in humans (e.g. Dhaenen, 1996), is likely to also be pleasurable in a diurnal rodent such as a striped mouse that chooses to lie down in the 
sun when risks of predation are low (Schradin et al., 2007). Beyond analogies with humans self-reporting their feelings, additional evidence to support inferences regarding the affective valence of inactive animals' states can also come from pharmacological corroboration, e.g. testing that a specific form of inactivity is reduced by anxiolytics and/or increased by anxiogenics if it is believed to reflect fear. This provides evidence of construct validity and, in cases where a range of treatments was tested, discriminant validity (see e.g. Cronbach and Meehl, 1955). In this review, we briefly discuss how inactivity is defined and assessed in the literature, and then discuss how it relates to affective (welfare) states. In humans, affective states can be categorized in terms of two fundamental underlying dimensions: the valence i.e. whether the experience is perceived as negative or positive, punishing or rewarding, unpleasant or pleasant- and the reported activation - i.e. high or low arousal (e.g. Russell and Barrett, 1999). Theoretical and empirical studies (reviewed in Mendl et al., 2010) suggest that negative high-arousal affective states (e.g. feeling fearful) are principally associated with perceiving and reacting to threats or dangers, while negative low-arousal states (e.g. feeling sad) are likely to be associated with experiences of loss or lack of reward, and may promote low activity and energy conservation when resources are lacking. Positive high-arousal affective states (e.g. excitement) are likely to be associated with appetitive motivational states, and function to facilitate seeking and obtaining rewards; while positive low-arousal affective states (e.g. calmness) are instead expected to be associated with low levels of experienced threat, perhaps facilitating the expression of maintenance activities. In this paper, we rely on this framework in order to categorize affective states, and those specific forms of inactivity associated with such states. This classification of specific forms of inactivity displayed by animals will be supported by linguistic self-reports collected in humans displaying phenotypically similar inactivity in similar situations, and, when possible, by pharmacological validation. 


\section{How is inactivity defined and measured?}

Although inactivity may seem fairly straightforward to define, there is some variation in exactly what the term encompasses. In some cases, the hypotheses under test relate to specific forms of inactivity (e.g. in rats: sleeping, or lying non-alert with both eyes closed: AbouIsmail et al., 2008; freezing, a complete absence of visible movement except breathing: Fanselow, 1982), and so only those forms are assessed. However, in other cases, its operational definition seems to be a by-product of the methods used to assess activity. This usually occurs when inactivity is not the main focus of the study but is measured simply as a part of the time budget or to control for 'activity' levels because they influence the variable of interest. When it is studied in free-living animals, activity is usually assessed using radiotracking or similar technology, and so any time not in locomotion is called inactivity. Some studies of captive animals similarly equate 'activity' with locomotion. Laboratory animal research, for example, often infers activity levels from proxy measures such as the number of entries into closed arms (and therefore locomotion) in the elevated plus maze, a test of anxiety (e.g. Louvart et al., 2005), while some agricultural studies use pedometers (e.g. O'Callaghan et al., 2003). Therefore, inactivity in those studies would include time spent stationary but performing purposeful movements such as grooming. However, in applied ethology research using video or live observation, any movement is typically considered activity, even if the animal remains in one place; for example, kicking (e.g. Rushen et al., 2001) and eating (e.g. Rochlitz et al., 1998; Burrell and Altman, 2006) are not categorized as inactive. Thus, the most common definition of inactivity is being relatively motionless, and although it is rarely stated explicitly, this means no movement with an apparent function (e.g. grazing or chewing a bite of food) but would include other slight movements (e.g. turning the head or shifting positions). Finally, research on anticipatory behaviour sometimes discusses 
167 hyperactivity or decreases in activity during anticipation, but actually measures the number of

168

169

170

171

172

173

174

175

176

177

178

179

180

181

182

183

184

185

186

187

188

189

190

191

behavioural transitions rather than total amount of time spent moving or stationary (e.g. van den Bos et al., 2003). Studies using any of these definitions of inactivity will be discussed here.

\section{Increased inactivity / decreased activity as a sign of poor affective states}

Increased inactivity likely to be associated with negative affective states will be considered here, distinguishing specific forms of inactivity expressed in response to a perceived threat (likely to be associated with negative high-arousal affective states, Mendl et al., 2010, cf. Introduction) from those expressed in situations where threat levels but also chances of getting rewards are low (likely to be associated with negative low-arousal affective states).

\subsection{Increased inactivity / decreased activity displayed in response to a perceived threat}

Inactivity that may occur in response to a perceived (frightening) threat stimulus will be presented here, targeting more specifically the freezing, tonic immobility and hiding responses.

Freezing (sometimes also termed attentive immobility) is a common response in the face of an immediate (perceived) threat in various species, where an individual becomes abruptly motionless, monitoring a perceived source of danger (reviewed by Boissy, 1995). A 'freezing-like' state, characterised by increased immobility and rigidity (quantified using a force platform) and a reduced heart rate (also termed 'fear bradycardia'), has been described in humans. This state has been observed in healthy people viewing pictures of mutilation (that they self-rated as negative in valence and high in arousal) compared to neutral or 
positively rated pictures (Azevedo et al., 2005; Facchinetti et al., 2006), as well as in patients diagnosed with panic disorders when seeing either pictures of mutilation or images that were anxiogenic due to their pathologies (e.g. crowded areas for agoraphobic patients), compared to neutral pictures (Lopes et al., 2009).

$$
\text { In animals, freezing is used to quantify fearfulness in many behavioural tests (see e.g. }
$$
Bouton and Bolles, 1980; Forkman et al., 2007). It has been particularly well-described in rodents, on which we will focus here, and can be operationally defined as 'the absence of all visible movement of the body and vibrissae, except for movements necessitated by respiration' (Fanselow, 1982). The description can also include (species-specific) postural elements, such as a 'characteristic immobile, crouching posture' in rats, and autonomic changes, i.e. a decreased heart rate (similarly to the 'fear bradychardia' recorded in freezing humans) and an increased respiratory rate (Fanselow, 1984). Freezing can be induced by exposing rats to a predator odour (e.g. Wallace and Rosen, 2000; Knox et al., 2012), as well as to conditioned stimuli or contexts paired with aversive experiences (electric shocks: e.g. Fanselow, 1984; Richmond et al., 1998; Luyten et al., 2011; carbon dioxide inducing dyspnoeic suffocation: Mongeluzi et al., 2003). The more intense the aversive stimuli are, the longer the rats remain frozen (Fanselow and Helmstetter, 1988; Wallace and Rosen, 2000; Mongeluzi et al., 2003; Santos et al., 2005, but see Leaton and Borszcz, 1985 for nonmonotonic effects). Freezing is 'not a simple suppression of activity' (Fanselow, 1984) but a highly aroused state (Bracha, 2004): rats' percentage of time spent freezing when exposed to a conditioned stimulus previously paired with electric shock was positively correlated with the amplitude of their acoustic startle response in the presence of that conditioned stimulus (Leaton and Borszcz, 1985). Interestingly, neither food deprivation (an aversive experience but not assumed to induce 'fear', Maren and Fanselow, 1998; Heiderstadt et al., 2000), nor exposure to smells unrelated to predation (e.g. butyric acid, banana and pear odours, Wallace 
and Rosen, 2000; Knox et al., 2012) induce freezing responses. Moreover, in rats where the risk of infanticide by unrelated adult males ends around weaning, exposure to a sexually experienced, unrelated male rat induces freezing in young rats only before they reach a natural weaning age (around $26 \mathrm{~d}$ ), whereas exposure to a cat odour (a predation risk relevant during all life stages) induces the freezing response in rats before and after weaning age (Wiedenmayer and Barr, 2001). Additional evidence that the freezing response is associated with negative valence in rodents comes from pharmacological corroboration: in rats, while freezing in response to a cat exposure was gradually suppressed over repeated daily exposure (Farook et al., 2004), administration of anxiogenic drugs restores the freezing behaviour. Conversely, the administration of anxiolytic drugs (e.g. midazolam, diazepam) reduces the duration of rats' place-conditioned freezing response (Fanselow and Helmstetter, 1988; Verleye and Gillardin, 2004; Santos et al., 2005).

Another specific form of inactivity also displayed in response to a threat in various species is tonic immobility (TI) (e.g. Gallup et al., 1971b). In humans, 'TI-like' states are characterised by a temporary behavioural state of motor inhibition, associated with tremors, eye closure, increased breathing, and coldness, and have been reported to occur in response to situations involving intense fear and physical restraint such as interpersonal trauma (sexual assault, torture, armed robbery) ${ }^{2}$ (Galliano et al., 1993; Abrams et al., 2009). Although such studies are non-experimental in nature (and therefore results may not be generalised to any human population), TI-like responses appear to be far from uncommon. For example, across several studies reviewed in Galliano et al. (1993), from $12 \%$ to $50 \%$ of the studied victims of rape/sexual assaults were 'paralyzed' motionless and did not resist their attackers in any way. Displaying TI-like responses during traumatic episodes has also been reported to positively

\footnotetext{
${ }^{2}$ Although less studied, intense fear associated with accident-related trauma and the unexpected death of a loved one have also been reported to sometimes induce a TI-like state in humans despite not involving physical restraint.
} 
correlate with longer-term psychological impairments such as depression, anxiety and Post-

Traumatic Stress Disorder (Abrams et al., 2009; Volchan et al., 2011). In laboratory studies,

'standing still (paralyzed with fear)' is one of the defensive strategies subjects predicted they would display in response to threat scenarios involving nearby threat stimuli and inescapability of the threat/situation, such as 'Late at night you are alone in an elevator. When it stops and the doors open, a rough looking stranger gets in fast to attack you, blocking your exit' (Blanchard et al., 2001; Shuhama et al., 2008). particularly well-described in birds, where it has been defined as a 'reversible state of 250 ('catatonic-like') profound motor inactivity following brief exposure to physical restraint (e.g. 15s), which may last from a few seconds to over several hours' (e.g. Gallup et al., 1971b). It is also characterised by a suppression of vocalisation, as well as TI-specific (not observed in freezing) muscle tremors in the extremities and intermittent eye closures. As for freezing, physiological correlates include bradycardia and increased respiratory rate, as well as a TI-specific (not reported in freezing) decrease in body temperature (e.g. Gallup et al., 1971b; Nash et al., 1976). TI is an aroused state: electroencephalographic activity in animals displaying TI has been reported to be often the same as that of waking animals (e.g. in rabbits: Klemm, 1966; in opossum Didelphis virginiana: Barratt, 1965, review in Gallup, 1974; Whishaw et al., 1982). A 'TI-like' response has also been described in certain domestic goats, known as 'fainting' goats becoming 'perfectly rigid when suddenly surprised or frightened' (Lush, 1930). This response is caused by a hereditary genetic disorder (congenital myotonia, Clark, 1939), although physiological correlates of this state have not been investigated. In birds (chicks unless otherwise specified), a variety of aversive manipulations before TI induction increase the TI duration and/or propensity of the bird to display the TI state, including exposure to electric shocks or to conditioned stimulus signalling shocks 
266 (Gallup et al., 1970; Gallup, 1973), rough handling (bird inverted for 30s: laying hens and 267 broilers, Jones, 1992), and exposure to loud noise (Gallup et al., 1970). While freezing in rodents appears to be a risk-assessment behaviour to a (perceived) distant threat (Blanchard et al., 2011), TI happens following physical restraint, and has been suggested to be an antipredation response even after the animal has been captured. Such 'death-feigning' might induce the predator to loosen its hold (Gilman et al., 1950; Engel and Schmale, 1972; Sargeant and Eberhardt, 1975; see Thompson et al., 1981 for evidence TI can deter predators). This response seems specific to fear-inducing situations: food-depriving chickens, which is aversive but not likely frightening, does not increase these animals' TI duration (Gallup and Williamson, 1972). Additional evidence supporting the negative valence and high arousal of the TI response in birds comes from pharmacological validation: in chicks, pre-TI-induction administration of adrenaline (Braud and Ginsburg, 1973) and corticosterone (Jones et al., 1988) increases the TI duration and/or the propensity of birds to display TI, while a pre-TI-induction tranquilizer injection reduces the duration of the TI response (Gallup et al., 1971a).

Another -- perhaps less species-specific -- form of inactivity that can be displayed in response to a perceived threat is hiding. In humans, hiding (protecting oneself behind something) is one of the defensive strategies chosen by subjects in laboratory studies in response to fearful threat scenarios such as 'Late at night... you are sleeping alone in your bed. You suddenly wake up feeling that you heard a suspicious noise'. Not surprisingly, the presence of a place of concealment or protection in the scenario promoted the hiding choice; so did distant (rather than close) threat stimuli (Blanchard et al., 2001; Shuhama et al., 2008). In animals, hiding can be defined operationally using location (provided that there are locations suitable for hiding in the environment): hiding animals are 'remaining stationary 
and out of sight or camouflaged using any kind of shelter or visual barrier' (Meagher et al., 2013). In rodents, exposure to a predator or to its odour initially induces a hiding response (e.g. rats exposed to a worn cat collar: Dielenberg and McGregor, 1999; mice repeatedly exposed to a rat moving around on top of their cages: Dalm et al., 2009). In laboratory cats, exposure to complex stressors (involving unpredictable mildly aversive procedures) increases time spent awake/alert and attempting to hide, and suppresses active exploratory and play behaviour (Carlstead et al., 1993b). Translocation to novel environments also induces hiding in felids (leopard cats: Carlstead et al., 1993a; quarantined domestic cats: Rochlitz et al., 1998). There is also pharmacological evidence to help infer the negative valence and high arousal of the hiding response: in rats, anxiolytic administration (the benzodiazepine drug midazolam) reverses rats' hiding response to a worn cat collar (Dielenberg and McGregor, 1999), and increases the proportion of time spent exploring in open arms in an elevated plus maze, while anxiogenic substances (e.g. caffeine) increase the time spent hiding in the closed arms of the maze (Pellow et al., 1985).

Freezing, TI and hiding are specific forms of inactivity expressed in response to a (perceived) actual or potential threat, both in humans and in animals. In both, they are reduced by anxiolytics and increased by anxiogenic drugs. Freezing, TI and hiding therefore appear to be valid indicators of a negative, highly aroused affective state, and to date, our best examples that specific forms of inactivity can be used as trustworthy indicators of specific affective states (in this case, 'fear-like' states) in animals. 

rewards are low (likely to be associated with low arousal negative affective states: Mendl et al., 2010, see Introduction) will be discussed here, specifically targeting sickness, depression-like, and boredom-like conditions.

\subsubsection{Inactivity and ill-health}

Lethargy (i.e. a state of decreased mental activity, characterised by sluggishness, drowsiness, inactivity, and reduced alertness, APA, 2013) is a well-established component of sickness behaviour, which is the 'coordinate set of subjective, behavioural and physiological changes that develop in sick individuals during the course of an infection' (Dantzer, 2004).

'Sick individuals are somewhat depressed and lethargic' and 'show little interest in their surroundings and stop eating and drinking' (Dantzer, 2004). Reduced activity here is considered a strategy of energy conservation in order to allow the full development of a fever (which is associated with and plays a critical role in recovery from many pathogenic infections), and so has an eventual benefit. However, this inactivity is very likely linked with negative affective states, as it is 'very often accompanied by pain' (Dantzer, 2004), and in humans, a transient depressive state has been reported to occur as an infectious episode develops (Aubert, 1999). Sickness behaviour is common to many mammalian species (Hart, 1988; Maes et al., 2012): 'lethargy', 'listlessness and disinterest in social interactions with the environment', 'behavioural inhibition', and 'reduction of locomotor activity, exploration and grooming' have also been observed in sick animals. For instance, rats challenged with bacterial and viral mimetics show decreased voluntary running wheel activity and, broadly, less movement in their home cage (Hopwood et al., 2009). The general decrease in

338 behavioural activities in sick animals has been shown to reflect changes in motivational state 339 rather than a simple consequence of weakness: for example, if pups are removed from the 
nest of lactating mice whose behavioural activity is depressed by LPS injection, the sick mothers interrupt their sickness behaviour to bring the pups back to the nest, then return to inactive recuperative behaviour (Aubert, 1999). As in humans, lethargy in sick animals is likely to be associated with negative affect, such as pain (e.g. in dogs: Wiseman et al., 2001). Perhaps more broadly, ill-health in humans (including not only infectious sickness but e.g. injury, post-operative conditions, and chronic back disorders) reduces both voluntary (e.g. work, recreational) and obligatory (e.g. self-care) activities (e.g. Tait et al., 1990). It seems to have the same effect in animals: poor health conditions can increase the proportion of time spent awake but lying down (e.g. postoperative pain in rabbits: Leach et al., 2009 and horses: Pritchett et al., 2003; ear notching and tagging in piglets: Leslie et al., 2010; lameness in 350 dairy cattle: Chapinal et al., 2010; Calderon and Cook, 2011 and in broilers: Weeks et al., 2000), whereas analgesia reduces time lying down in lame animals (e.g. dairy cattle: Schulz et al., 2011; Offinger et al., 2013). Adult zebrafish (Danio rerio) injected with acetic acid (a noxious chemical stimulus) display decreased swimming activity (Correia et al., 2011; but see Steenbergen and Bardine, 2014 for an opposite effect on zebrafish larvae water-exposed to acetic acid). High activity of a shoal could thus indicate that its members are healthy, and joining it could be beneficial for fitness (e.g. active fish can be quicker to find food patches and more confusing for predators), which might be part of the reason that, although shoaling zebrafish usually prefer to join larger shoals, this preference can be shifted to a smaller shoal

359 if its members are comparatively more active than the fishes in the larger shoal (Pritchard et al., 2001).

Poor health conditions associated with negative affective states such as pain, appear to increase inactivity, both in humans and in animals, in each of which they are reduced by

363 analgesic drugs. Such inactivity is therefore likely to be associated with negative affective 364 states. Poor health-induced inactivity is, however, less specifically described (i.e. overall 
increased inactivity / decreased activity) than, for example, those forms of inactivity displayed in response to a perceived threat. The presence of signs of ill-health (e.g. fever,

367 injury) and/or knowledge of specific contexts in which inactivity increases (e.g. post-surgery)

368 therefore appears crucial to infer the affective state associated with such inactivity.

\subsubsection{Inactivity and depression-like states}

In humans, clinical depression -- by which we mean 'major depressive disorder' or (International Statistical Classification of Diseases and Related Health Problems, World Health Organisation [WHO], 1994) terminologies -- is a common mental illness diagnosed by the co-occurrence of several affective, cognitive and behavioural symptoms. These include a 'depressed (low, sad) mood most of the day, nearly every day, as indicated by either subjective report (e.g. feels sad, empty, hopeless) or observation made by others (e.g. appears tearful)' (APA, 2013, P160). A common trigger is chronic stress, such as that arising from aversive life events or chronic pain or illness (Blackburn-Munro and Blackburn-Munro, 2001; Siegrist, 2008; Hammen et al., 2009; APA, 2013). Cognitive changes can be associated with depression and may act as mediators in some subjects, being hypothesised to contribute to the onset and/or maintenance of the disease (Beck, 1967; Gotlib and Krasnoperova, 1998).

384 One such change, 'learned helplessness', is proposed to occur 'when highly desired outcomes 385 are believed improbable or highly aversive outcomes are believed probable, and the individual comes to expect that no response in his repertoire will change their likelihood' 387 (Abramson et al., 1978).

With respect to inactivity, a low, sad mood may induce increased inactivity even in 389 healthy people. For instance, Rucker and Petty (2004) showed that inducing sadness in 

passivity (a vacation resort framed as a place to relax and rest), while inducing anger yields a preference for a product promoting activity (a vacation resort framed as a place to enjoy sports and activity). Accordingly, clinically depressed patients have been reported to be more 394 inactive -- by which we mean here a decrease in a variety of daily activities -- than their nondepressed counterparts. This includes "not doing fun activities or chores that need to be accomplished' (Knowles, 1981), and reported difficulties initiating or completing social and non-social activities (Baker et al., 1971; Schelde, 1998; APA, 2013). Reduced physical 398 activity (both mild, such as walking and gardening, and more vigorous, such as playing 399 sports) has been associated with clinical depression (Seime and Vickers, 2006; Lindwall et al., 2011), while - cautiously ${ }^{3}$ - increased exercise has been reported in several reviews or meta-analyses to improve depressed mood and/or anxiety (e.g. Byrne and Byrne, 1993; Dunn et al., 2001; Seime and Vickers, 2006; Davis and Dimidjian, 2012). contexts), be experiencing 'depression-like' states? ${ }^{4}$ Presumably yes: dogs and cats (e.g. Fox, 1968, p. 357) and elephants (Mason and Veasey, 2010) have anecdotally been suggested to become highly inactive when deprived of their owners or after the loss of a social companion, as have apes housed long-term in barren environments in laboratories or zoos (e.g. Engel, 408 2002, p174; Brune et al., 2006), and socially deprived monkeys (e.g. Harlow and Harlow, 409 1962; Harlow and Suomi, 1974; Suomi et al., 1975). Because the aetiology corresponds to

\footnotetext{
${ }^{3}$ Due to methodological biases present in one or more of the studies included in the review / meta-analysis, e.g. people are not systematically randomly assigned to treatment groups and/or there are potential confounds or no control groups and/or the amount of physical activity applied as a treatment is based on patients' self-reporting (no verification) and/or conclusions are expanded from normal subjects to clinical samples. These biases, however, are spread across individual studies, and a variety of biological and psychological mechanisms could explain the reported benefit of exercise on mood, cautiously suggesting that this commonly report effect might be a 'trustable' phenomenon.

${ }^{4}$ Discussing in detail whether or not non-humans can become clinically depressed-like - i.e. show states that share the same or most of the properties of those described in clinically depressed patients -- would go beyond the scope of this paper. However, even if the quality and quantity of current evidence are not yet sufficient to conclude this with certainty, both circumstantial and experimental evidence have led several authors (including us) to hypothesise that depression-like states occur in other animals as well (see e.g. Ferdowsian et al. 2011; Hennessy et al., 2014; Fureix et al., 2015).
} 
theories of human depression emphasizing aversive life events and chronic stress as a common trigger, such inactivity is likely to be associated with negative affect.

Moreover, the cognitive feature of learned helplessness has also been shown in animals, and is a phenomenon typically accompanied by an overall decrease in activity (see e.g. Mineka and Hendersen, 1985). Indeed, although the term learned helplessness referred initially to a deficit in avoidance learning induced by repeated exposure to uncontrollable shock (reviewed by e.g. Maier and Seligman, 1976), the meaning of the label has now been expanded; it is sometimes applied to any 'passive' behaviour (i.e. quiescence or the absence of active responses to stress, such as escape attempts; cf. Oxford English Dictionary, 2005) that appears to result from exposure to uncontrollable stressors (Maier, 1984; see also Wemelsfelder, 1990; Carlstead, 1996). For instance, sheep moved from pasture to inescapable indoor crates (Fordham et al., 1991) and laboratory rodents placed in an inescapable container filled with water (known as the Porsolt Test, reviewed in e.g. Deussing, 2006), both begin by reacting to the situation with agitation, but end up displaying inactivity and unresponsiveness. According to the above-mentioned expanded definition, this eventual response would reflect learned helplessness. Again, because the aetiology corresponds to cognitive theories of human depression (Beck, 1967; Abramson et al., 1978; Gotlib and Krasnoperova, 1998), this inactivity is believed to be a depression-like behaviour, and therefore associated with a negative affective state. In mice and rats that 'cease struggling and remain floating motionless in the water, making only movements necessary to keep their head above water' (Porsolt et al., 1977) in the Porsolt test, additional support comes from the fact that this specific form of inactivity is both amplified by stressors and alleviated by antidepressants (Porsolt et al., 1977; Cryan et al., 2002; Matthews et al., 2005; Deussing, 2006; McArthur and Borsini, 2006). It also co-varies with other depression-like symptoms, such as anhedonia (Strekalova et al., 2004), i.e. the loss of pleasure, a key feature of human 
clinical depression (APA, 2013). The hypothesis that the term learned helplessness might also

436 be applicable to captive animals that seem very passive or inactive in their home environment

437 is also supported by findings that animals reared in socially isolated and/or barren cages are

438 more vulnerable to developing learned helplessness in avoidance learning paradigms than

439 those reared in more socially and physically complex, and presumably controllable, 440 environments are (Seligman, 1972; Chourbaji et al., 2005).

441 Finally, Fureix and colleagues $(2012,2015)$ recently described long-lasting inactive 'withdrawn' states in certain riding horses, characterised by bouts of unresponsiveness,

443 remaining motionless with unblinking eyes with an apparently fixed gaze (reminiscent of the 444 reduced responsiveness and reduced interactivity of some depressed human patients) and 445 anhedonia. These states also correlate with stereotypic behaviour (a possible marker of current, but also past exposure to stressors). While the aetiology of this specific form of inactivity is currently unknown, its association with key features of human clinical depression 448 makes it likely to be associated with negative affect.

Do these findings demonstrate with certainty that these inactive animals are clinically depressed, in the same way as depressed patients showing decreased variety in their daily activities? The quality and quantity of current evidence are not yet sufficient to conclude this. Moreover, while some forms of inactivity are highly specific ('floating' in rodents, 'withdrawn' states in horses), others are not (e.g. passivity when exposed to inescapable, uncontrollable stressors). However, that inactivity appears in contexts similar to those that trigger the appearance of clinical depression in humans, or co-varies with key symptoms of this pathology (e.g. anhedonia) is sufficiently consistent with the hypothesis to make additional research into these topics, including how this inactivity would be modulated by 458 anti-depressant drug treatments, very worthwhile. 
Boredom is a negative affective state induced by monotony or lower-than-optimal levels

462 of stimulation. In addition to self-report, this definitional link to negative affect is supported

463 by evidence of high motivation to avoid the state; for example, boredom-prone people show a

464 preference for activities that are perceived as risky and therefore frightening to most people,

465 but that increase stimulation levels, such as bungee-jumping (Michel et al., 1997). Selfreports, however, are key to identifying boredom and situations that induce it (Harris, 2000).

Berlyne, 1960 for an alternative possible time course) and thus in some cases, restlessness may be seen rather than inactivity (reviewed by Kirkden, 2000). Imposed inactivity can also be a cause of boredom (Berlyne, 1960; Heaman and Gupton, 1998). Most theoretical discussion categorizes boredom as a state of under-arousal (e.g Fiske and Maddi, 1961; Stevenson, 1983; Mikulas and Vodanovich, 1993) given its association with low stimulation, although Berlyne (1960) postulated that prolonged monotony can lead to increases in arousal; others have similarly considered boredom simply as a state of 'non-optimal' arousal (Eastwood et al., 2012). While there is some evidence from humans that arousal may sometimes be elevated during boredom (e.g. EEG data from subjects exposed to sensory 478 deprivation after sleeping as much as possible: Berlyne, 1960), other studies have found 479 decreasing arousal over time when engaged in a boring task (e.g. Pattyn et al., 2008). Also 480 supporting the association with under-arousal, and thus supporting its inclusion in this section 481 of our discussion, methods of avoiding boredom are likely to increase arousal: these include 482 consumption of recreational drugs (Samuels and Samuels, 1974), which commonly include 483 stimulants (Boys et al., 2001), and participation in thrill-seeking activities, as previously 484 mentioned. 
Due to the dependence on self-reported affect for identifying boredom in humans, this state has been subject to little empirical investigation in animals, where self-report is

487 impossible and thus affect cannot be assessed directly. However, captive animals commonly 488 face monotonous environments, often less complex or lower in stimulation than those in 489 which their ancestors evolved (in some cases, even those they experienced themselves early 490 in life). For this reason, theory suggests that they would also find such situations aversive. 491 For example, McFarland (1989) proposed that when captive animals' immediate physical needs are met but they cannot pursue other activities that would occupy their time in the wild such as reproduction or mating, they are left in a state of 'limbo' and are likely to suffer 494 because most species will not have evolved methods of coping with such a situation. Veissier 495 et al. (2009) also argue that since sheep are sensitive to the same features of stimuli that 496 induce boredom in humans, they are potentially capable of experiencing it; the same argument could be applied to many species. Inactivity is generally accepted as a common consequence of housing in relatively barren cages or enclosures and interpreted as a sign of poor welfare (DeMonte and LePape, 1997), which many people attribute to boredom (e.g. Stevenson, 1983; Woodgush and Beilharz, 1983). Conversely, increasing activity or behavioural diversity through provision of opportunities to interact with stimuli is assumed to improve welfare (e.g. pigs: Woodgush and Beilharz, 1983; chimpanzees: Celli et al., 2003; dogs: Wells, 2004). Sometimes this assumption has been supported by improvements in other 504 welfare indicators (e.g. Paquette and Prescott, 1988) or by animals' preference for the 505 enrichment (e.g. Rozek et al., 2010).

Both the use of the term 'boredom' in animals and its relationship to inactivity still need validation, however. To provide a starting point for this work, Meagher and Mason (2012) 508 proposed an operational definition based on motivation to obtain stimulation, which should 509 be a universal symptom. The validity of this operational definition was supported by the fact 
510

511

that this motivation was elevated in captive mink housed in non-enriched cages, predicted to experience more boredom-like states. Thus, compared to mink housed in a preferred (Dallaire et al., 2012) and more stimulus-rich environment, the mink behaved as bored humans would. This method of assessment relied on measuring activity when given an opportunity to avoid boredom rather than directly assessing inactivity in the hypothesized boredom-inducing situation, because the latter might vary with time and between individuals (as in humans), among other reasons. However, the study also identified a tentative link between the apparent boredom and a specific subtype of inactivity when undisturbed in the home cage (lying down with the eyes open). Future work could use self-administration of stimulants to further validate the concept of boredom in barren-housed animals and its association with inactivity, predicting that very inactive individuals in non-enriched cages would be most likely to selfstimulate. At least until such work has been carried out for a given species, inactivity should be used as an indicator of boredom with extreme caution: although high levels of inactivity in monotonous environments may well be associated with boredom, the alternative response of restlessness would make this indicator prone to false negatives (see also 5.1.), in which an environment that is in fact boring does not increase group-level or even individual-level inactivity levels.

\section{Increased inactivity / decreased activity as a sign of good affective states}

$$
\text { Increased inactivity or decreased activity likely to be associated with positive affective }
$$
states will now be discussed, again distinguishing inactivity likely to be associated with high and low-arousal positive states. 

highly-aroused affective states

536 As stated in the Introduction, positive, highly-aroused affective states are likely to be 537 associated with appetitive motivational states, and function to facilitate seeking and obtaining 538 rewards (Mendl et al., 2010). Being inactive in order to favour reward acquisition sounds 539 intuitively unlikely to happen, and examples are rare even in humans, with perhaps the exception of yogi meditation, which has been self-reported by meditators to be a highlyaroused pleasant state (Cahn and Polich, 2006). Chess players close to winning a game and

542 focused on choosing the best strategy could also perhaps experience a highly-aroused and 543 pleasant motionless state; this is likely one example of what Csikszentmihalyi (1975; 1990) termed a "flow" state. Flow states involve being concentrated on a task that is achievable but sufficiently challenging to require focused attention and skill, and are self-reported as being enjoyable, at least in retrospect (reviewed in Csikszentmihalyi 1990). However, although the

547 absence of evidence is not a proof of absence, one may reasonably doubt that animals 548 practice meditation or play chess. An animal example in this category might be cats 549 'stalking': adults stalking prey (Wise, 1974) and kittens playing (Bateson and Young, 1981) 550 temporarily restrain any movement and stay perfectly motionless. Cats have been considered to become 'hypoactive' while anticipating food rewards, displaying reduced behavioural transitions between the offset of a conditioned stimulus and the onset of an unconditioned

553 stimulus in a Pavlovian conditioning paradigm (van den Bos et al., 2003). According to the authors, this might be expected as 'they [cats] normally employ a 'sit-and-wait' tactic while close to their prey'. Bouts of immobility while stalking could therefore tentatively be seen as

556 a (cat-specific) form of inactivity that would favour reward acquisition, but the affective 557 state(s) associated with such a behaviour are clearly not validated yet (see e.g. Bassett and 
558 Buchanan-Smith, 2007 for evidence that opposite affective states are sometimes associated 559 with anticipation).

560

561

562

563

564

565

566

567

568

569

570

571

572

573

574

575

576

577

578

579

580

581

582

4.2. Increased inactivity / decreased activity likely to be associated with positive low-arousal affective states

Increased inactivity expressed in situations with low levels of experienced threat, and that facilitates the expression of maintenance, consolidation and recovery (cf. Introduction) will be discussed here, targeting more specifically 'sun-basking' and post-consummatory inactivity. Note that resting will be discussed later (see part 5.4.).

\subsection{1. 'Sun-basking' inactivity}

In humans, UV exposure activates known reward centres in the brain (Harrington and colleagues 2012, cited in Fell et al., 2014), and lying in the sun or, in other words, 'sunbasking', has hedonic properties (Dhaenen, 1996; Loas et al., 2000); it might even turn into an addictive behaviour (Fell et al., 2014). According to Balcombe (2009), 'animals' lives afford them the opportunity to experience a wealth of other pleasures beyond the realms of food, sex and touch, such as basking in the sun or seeking shade'. Supplying captive wombats (Lasiorhinus latifrons) with feed and olfactory items (so-called enrichments, but note that such items did not reduce the time spent displaying stereotypic behaviours in this study) tends to increase the time animals spent awake in lateral recumbency in direct sunlight, or in the authors' terms, 'sun-basking' (Hogan et al., 2010). Moreover, evolutionary perspectives predict that behaviours that help maintain homeostasis and promote evolutionary fitness are likely to often produce rewarding sensations (Cabanac, 1971; Fraser and Duncan, 1998). Tawny frogmouths (Padargus strigoides; Kortner and Geiser, 1999) and diurnal striped mice (Rhabdomys pumilio; Schradin et al., 2007) do chose to stand motionless or lie awake in 
583 direct sunlight in cold conditions, a so-called 'sun-basking' behaviour that presumably helps

584 maintain homeostasis by facilitating passive thermoregulation and removes the aversive

585 feeling of coldness. Similarly, poikilothermic animals actively chose to sun-bask until their

586 body temperatures reach their preferred body levels (e.g. in turtle Pseudemys Scripta,

587 Crawford et al., 1983; in Nile crocodile Crocodylus niloticus, Downs et al., 2008; in blue

588 spiny lizard Sceloporus cyanogeny, Garrick, 1979). Interestingly, Fell et al. (2014) have

589 recently shown that chronic low doses of UV exposure elevate laboratory mice plasma levels

590 of $\beta$-endorphin, an endogenous opioid known to play a role in reinforcement. While one may

591 question the biological relevance of UV exposure in a nocturnal animal, these results

592 nevertheless suggest that sun-basking could have biologically relevant rewarding properties

593 in diurnal rodent species, such as the above-mentioned striped mouse (Schradin et al., 2007).

594 Thus, although the evidence is not yet conclusive, additional empirical tests of the hypothesis

595 that sun-basking is pleasurable in animals, as in humans, seem very worthwhile (e.g. in

596 domestic cats, anecdotally reported by their owners to lie down in certain areas at the time of

597 the day these areas are sunny: Fureix, personal observation).

598

599

4.2.2. Post-consummatory inactivity

600 Post-consummatory inactivity, such as inactivity immediately expressed post-copulation,

601 is likely to be associated with satisfaction and to be pleasurable. In humans, experiencing 602 sexual arousal to orgasm usually produces a pleasant calming effect of sexual satisfaction 603 (Graber et al., 1985; Levin, 2007), and partners frequently remain relatively inactive during 604 the post-coital time (e.g. remaining awake and cuddling with the partner, or falling asleep,

605 Hughes and Kruger, 2011). Remaining inactive close to their mates after copulation has also 606 been reported in animals. For instance, in horses, immediately following ejaculation, the 607 stallion's body relaxes, and its head droops beside the mare's neck for a few seconds, after 
608 which the stallion dismounts and commonly stands quietly behind the mare, often relaxed and 609 inactive (Waring, 2003, P168). Rams similarly usually remain standing quietly beside the

610 female with their heads down slightly shortly after ejaculation and dismounting (Pepelko and 611 Clegg, 1965), while some mink remain motionless, as if sunk in deep stupor, for a period of 612 time after mating (Diez-Leon, 2014, personal communication). Mating mice generally fall 613 over onto their sides for 5-10 seconds immediately post-ejaculation whilst still coupled, with 614 open eyes and apparent unresponsiveness to sensory stimuli (e.g. being touched with a finger) 615 (Brennan, 2015, personal communication). Following evolutionary predictions (e.g. Cabanac, 616 1971; Fraser and Duncan, 1998) and by analogy with humans (Graber et al., 1985; Levin, 617 2007), sexual interaction and orgasm are typically likely to be pleasurable (see also Dixson, 618 2010, P392-393), at least in healthy male mammals (in which ejaculation can be observed).

619 Due to its very close temporal relationship with the sexual interaction, one may reasonably 620 hypothesize that this post-copulation inactivity in animals (or, at least, in male mammals) has, 621 just as in humans, a pleasant 'calming' affective component (see 4.2.3 and discussion for 622 further research suggestions).

623 Inactivity expressed in postprandial contexts could also be associated with positive 624 affective states. Postprandial inactivity is likely to be associated with satiety, i.e. in humans 625 the feeling of 'fullness' following a feeding episode (Benelam, 2009; Harrold et al., 2012), 626 and has been observed in a number of animal species (rats: e.g. Richter, 1922; Antin et al., 627 1975; Willner et al., 1990; Rodgers et al., 2010; northern harriers Circus cyaneus: Temeles, 628 1989; sows: Zonderland et al., 2004; dogs: Bosch et al., 2009; cats: Fara and colleagues 1969, 629 cited in Orr et al., 1997). Further evidence that postprandial inactivity in animals is likely to 630 be associated with satiety comes from pharmacological studies: cholecystokinin ${ }^{5}$ 631 administration, which in humans increases the feeling of fullness and reduces food

\footnotetext{
${ }^{5}$ a group of peptides localized in the gut in mammals
} 
632 consumption (e.g. Stacher et al., 1979; Crawley et al., 1982; Stacher et al., 1982; Sam et al., 633 2012), also reduces food consumption in animals (rats, mice, sheep, pigs, monkeys, reviewed

634 in Crawley et al., 1982), and induces inactivity (rats: e.g. Antin et al., 1975; mice: Crawley et 635 al., 1981; rhesus monkeys: Falasco et al., 1979). In calves, being able to suck on a teat 636 increases the tendency to rest after milk consumption (Veissier et al., 2002), and this may be 637 mediated in part by cholecystokinin, which increases in response to such sucking (De Passillé 638 et al., 1993).

639 Satiety can increase inactivity in humans as well (e.g. napping after lunch, Zammit et al., 640 1992; Vela-Bueno et al., 2008), although the causal relationship remains debated (review in 641 Campbell, 1992), making it difficult to use evidence regarding affective states during satiety642 induced inactivity in humans. Nevertheless, because satiated humans self-report positive 643 affective states, such as satisfaction and relaxation (Panksepp, 2005; Boelsma et al., 2010; 644 Seehuus et al., 2013), one may reasonably hypothesize that postprandial inactivity in animals 645 has a positive affective component just as humans experience after eating. This suggestion is 646 supported by the finding that, in laying hen chicks, denying access to the part of a pen 647 designed to accommodate postprandial inactivity results in a more negative affective state 648 than in a baseline situation (where chicks have free access to that area), as evidenced by a 649 more 'pessimistic-like' response in a judgment bias paradigm (Seehuus et al., 2013).

650 With respect to satiation, i.e. the processes that bring episodes of eating behaviour to an 651 end (Benelam, 2009; Harrold et al., 2012), ingesting food is typically considered activity in 652 applied ethology research (see section 2); satiation therefore appears unlikely to involve 653 inactivity in most species, including humans. However, rumination, which has the primary 654 function of facilitating clearance of digesta from the rumen by reduction of particle size, is 655 most frequently expressed when the animals are motionless lying down (Wagnon, 1963; 656 Kilgour, 2012; Schirmann et al., 2012). As such, it could be seen as a (ruminant-specific) 
657 satiation-induced specific form of inactivity. In humans, satiation is associated with positive 658 affective states, such as feelings of liking and satisfaction (e.g. Benelam, 2009; Seehuus et al., 659 2013), and lying down ruminating has been suggested to be 'a sign of relaxation in cattle' 660 (Phillips, 2002, from Espejo and Endres, 2007) and a sign that cows are 'at ease' (Bristow 661 and Holmes, 2007). Rumination also appears to decrease when animals are exposed to 662 aversive situations, such as social stressors (regrouping) and home-pen novelty (Schirmann et 663 al., 2011), disturbance by flies (presumably associated with discomfort: Wagnon, 1963, p47)

664 and ruminal acidosis (presumably associated with pain, lactating dairy cows: DeVries et al., 665 2009).

666

4.2.3. Inactivity and positive affective states: further research suggestions

Being inactive in order to favour reward acquisition is likely rare, with perhaps the only

669 direct evidence coming from humans during yogi meditation, as discussed above. Our other 670 suggested example, bouts of immobility while stalking in cats, is clearly not validated as an 671 indicator of positive affective states in animals. Potentially more fruitful as affective state 672 indicators are specific forms of inactivity reported in humans and expressed in animals when 673 threat levels are low, such as sun-basking and post-consummatory inactivity. All of these still 674 need validation, however. Further work could investigate to what extent acute stressors or 675 chronically aversive environments would decrease such inactivity (and the opposite for 676 preferred environments), how these forms of inactivity would be modulated by 677 pharmacological manipulations inducing either negative or positive affective states, and, 678 more specifically, whether the putatively positive affective state associated with postprandial 679 inactivity would be lessened in force-fed animals (see Faure et al., 2001 for evidence that 680 force-feeding might be perceived as aversive in ducks). Further research is also warranted 681 into other forms of inactivity likely to be pleasurable in humans, such as being passively 
rocked and breast-feeding, which could perhaps find equivalents in animals choosing to go and float in the water and in lactating females.

684

\section{Misinterpreting inactivity as an indicator of affective state}

We will further discuss the relationship between increased inactivity and affective states by presenting misleading situations prone to yield wrong conclusions. First, we will describe some examples of 'false negatives' (i.e. those cases where the animal's affective state is likely to be either poor or good but the animal is not inactive), and 'false positives' (i.e. those cases where the animal $\underline{i s}$ inactive, eliciting interpretations about its affective state, while the

691 animal actually does not experience the presumed affective state). We will then discuss specific forms of inactivity which appear to be not necessarily linked to an actual affective state, but instead to a lack of emotion, and how the methodologies used to assess inactivity

694 could yield different interpretations with regards to its associated affective states, discussing 695 in detail the case of resting.

696

697

\subsection{The risk of wrong conclusions: some examples of 'false negatives'}

698 As discussed above (sections 3 and 4), specific forms of inactivity and/or overall decreases

699 in activity in many contexts are likely to be associated with specific affective states; as such, 700 an inactive animal in a similar situation is believed to be in a more intense (negative or positive) affective state than its comparatively more active counterparts. Assuming this systematically would nevertheless sometimes yield incorrect conclusions; in some situations, animals are likely to experience the specific (negative or positive) affective states of interest,

704 but do not display increased inactivity. 
example) negative affective state. For instance, while individuals can respond to situations

708

709

710 involving a (perceived) threat by freezing or hiding, they can also display active reactions, such as fleeing or even attacking (Boissy, 1995; Blanchard et al., 2011). In red deer, the response strategies to a perceived threat differ according to age: juveniles employ a hiding strategy, and freeze in response to threat, but as they age, they begin fleeing from some threats instead (Espmark and Langvatn, 1985). This does not mean we should conclude that adult red deer are not afraid of the perceived threat from which they are fleeing only because they are not displaying inactive responses. More generally, personality can determine the form of an individual's response, including whether they become inactive or not. For example, speed of exploration of a novel environment is considered to reflect a personality trait in birds, and individuals with different exploratory phenotypes also differ in the degree to which they become inactive after social defeat (reviewed by Groothuis and Carere 2007). Van Reenen et al. (2005) thus suggest that their failure to find a correlation between open field locomotion and other measures of response to novelty might be explained by the presence of different coping styles, such that some calves responded to the open field with escape attempts, but others with immobility, novelty being nevertheless perceived as frightening in both cases. Moreover, an individual's experience is likely to influence its stress responses: for example, captive-born individuals may be more likely to respond actively to a sub-optimal captive environment, developing stereotypic behaviour, while wild-caught individuals may be more likely to respond by hiding (e.g. Jones et al., 2011; Camus et al., 2013). Despite these differences, individuals displaying both response types are likely to suffer from their sub-optimal life conditions.

Inactivity can also be one of two (or more) alternative responses - dependent this time on situational characteristics - to different situations associated with a similar (in this example negative) affective state. For instance, Cooper et al. (1996) showed that voles responded to an 
unfamiliar sound by freezing if in an enriched environment where cover was available, but otherwise responded actively, by running or digging; in such a case, there is no good reason to conclude that running or digging animals are not afraid of the unfamiliar sound simply because they do not freeze. Moreover, while ill-health (including painful) conditions increase inactivity in a number of species, including humans (see 3.2.a.), both increased and decreased sleep are used by caregivers as behavioural signs of pain in non-verbal cognitively impaired 738 children (McGrath et al., 1998), and animals sometimes also display active behaviours in response to ill-health conditions. For instance, in mice experiencing scrotal approach vasectomy, Leach et al. (2012) observed higher frequencies of pain behaviours (e.g. circle, flinch, stagger, twitch and writhe) and higher Mouse Grimace Scale (MGS) scores in the animals receiving a saline solution post-operatively, compared to pre-surgery periods and to 743 mice receiving post-operative analgesia (meloxicam, bupivacaine). Mice without postoperative analgesia are likely to experience pain; however, none of the inactive behaviours recorded in the study (e.g. 'stand' and 'sleep') differed pre- vs. post-surgery, nor between treatment groups. One may hypothesize that at least some of the active pain-related behaviours might allow animals to cope better with pain induced by the surgery than being inactive. Although this hypothesis remains to be tested in the context of that study, focusing only on the absence of increased inactivity here would lead to the conclusion that the mice experiencing scrotal approach vasectomy without post-operative analgesia do not suffer, which is contradicted by the displayed pain behaviours and MGS scores. Another example comes from a study on Pekin ducks (Anas platyrhynchos), in which animals were provided with environmental options allowing them to actively attempt to cope with the situation.

754 When injected either with saline solution or pathogen-associated molecular patterns, salineinjected ducks exhibited pronounced anorexia strongly correlated with a fever response, but none of the treatments significantly affected the level of animals' activity, measured by 
757 activity loggers surgically inserted into the abdominal cavity (Marais et al., 2013). According 758 to the authors, sick ducks might have actively attempted to lower their body temperature

759 during the defervescent phase of fever by getting in and out of the bathing tub provided. This 760 behaviour, which the authors had previously observed in ducks given pyrogens, would have 761 contributed to the amount of activity logged on the days when ducks were given pathogen762 associated molecular patterns.

763

764

5.2. The risk of wrong conclusions: some examples of 'false positives'

Erroneous interpretations might also come from those cases of 'false positives', where an animal $\underline{i s}$ inactive, raising interpretations about its affective state, while the animal's actual

767 affective state does not differ, or even goes the opposite direction, from the affective state of 768 its comparatively more active counterparts. For instance, if animals are afraid or motivated to hide but unable to do so because no appropriate camouflaged hiding places are available, their welfare is not likely to be better than if they were hiding (e.g. leopard cats: Carlstead et al., 1993a; Wielebnowski et al., 2002; mink: Nimon and Broom, 1999; shelter cats: Kry and Casey, 2007). Or, in other words, if animals are afraid or motivated to hide and able to do so because the cage provides them with a hiding place, there is no good reason to conclude that because they are inactive, their welfare is worse than the welfare of their counterparts who are in the same situation but prevented from hiding. Similarly, successful environmental enrichment often decreases inactivity in a wide range of species (e.g. Anna et al., 2002;

777 Koistinen et al., 2009; Rozek et al., 2010), with the exceptions to this rule being types of 778 physical enrichment that would primarily be expected to increase comfort or perceived safety, such as shelters (Wurbel et al., 1998a; Tilly et al., 2010); it would be absurd to 780 conclude that providing animals with shelters decreases their welfare. 
While the examples above highlight cases of false positives when inactivity is expected to

782 be associated with negative affective states, false positives can also happen when inactivity is

783 expected to be associated with positive affective states. For instance, Mason and Latham

784 (2004) found in a meta-analysis that stereotypic behaviours are more prevalent in populations

785 living in sub-optimal conditions than in populations kept under more welfare-friendly

786 conditions, but also that, more often than not, within populations where stereotypic behaviour

787 was prevalent, individuals that did not stereotype, or had relatively low levels of stereotypy,

788 had poorer welfare than those that with high levels, according to a variety of welfare

789 measures. Since non-stereotypic individuals are likely to be the most inactive individuals

790 within a population (e.g. Bildsoe et al., 1990; Wurbel et al., 1998b), this may indicate that at

791 an individual level, inactive responses to stressful conditions are actually more often

792 associated with poor welfare than with good welfare.

793

5.3. The risk of wrong conclusions: cases where inactivity is linked to a lack of emotion

While the examples above discuss specific forms of inactivity which are likely to be associated with (either negative or positive) affective states, some forms of inactivity appear to be not necessarily linked to an actual affective state but instead a lack of emotion. For instance, disorders of reduced motivation such as apathy, defined as 'a state of diminished

800 motivation in the presence of normal consciousness, attention, cognitive capacity, and mood'

801 (Marin and Wilkosz, 2005) ${ }^{6}$ involve decreased activity. In Marin and Wilkozs' words (our emphasis), 'patients with diminished motivation all show diminished activity'; however

803 they are also 'emotionally indifferent... or display restricted responses to important life

804 events'. Another example is a 'deconstructed state' observed in the pre-suicidal phase and in

\footnotetext{
${ }^{6}$ Apathy is not the only disorder of diminished motivation, but identifying the two other common disorders (abulia and akinetic mutism) relies on speech; therefore those states are not currently possible to operationalise in non-humans and of less interest here.
} 
805 socially excluded individuals, defined as a 'defensive state of cognitive deconstruction that 806 avoids meaningful thought, emotions and self-awareness, and is characterized by lethargy 807 and passivity and alerted time flow' (cited from Twenge et al., 2003, emphasis ours). In 808 animals, Engel and Schmale (1972) described a broad category of stress-induced forms of 809 inactivity that include decreased responsiveness to the environment, can persist over a long 810 period of time, and are believed to be adaptive because they reduce predation risk and allow the conservation of significant amounts of energy; they called this category conservationwithdrawal $(\mathrm{C}-\mathrm{W})$. The actual valence of the affective state associated with $\mathrm{C}-\mathrm{W}$, if any, is still debated, with some authors describing it as an 'affectively neutral' state (Weiner and

814 Lovitt, 1979).

815 While these forms of inactivity have (or, in the case of $\mathrm{C}-\mathrm{W}$, could have) no affective component at the time they are displayed, it seems worth noting that they all appear in negatively valenced contexts, and in humans, often yield situations from which individuals are likely to suffer, such as conflicts with relatives due to family burden. Therefore, even

819 though these specific forms of inactivity cannot be considered as indicators of the

820 individual's actual affective state, they should nevertheless be taken as a sign of exposure to suboptimal environments, and potential poor welfare.

\subsection{Different methodologies, different conclusions?}

824 As previously highlighted (section 2), there is some variation in the literature in exactly

825 what the term 'inactivity' encompasses. While how inactivity is assessed depends on one's perspective and hypotheses under test, methodological variation in terms of how behaviour is

827 categorized as inactive versus active is likely to yield some diversity in the effects observed 828 in terms of welfare states associated to inactivity. For instance, relying only on pedometers, 829 radio-tracking or similar technology -- where any time not in locomotion is called inactivity - 
830 would not discriminate e.g. a motionless healthy animal sun-basking (likely to experience 831 positive affective states, see 4.2.1) from an animal awake but inactive due to injury (likely to 832 experience negative affective states, see 3.2.1.).

833 A detailed example of how methodological variations in defining inactivity could

834 influence its interpretation in terms of associated affective states comes from resting. Resting

835 can be seen as a post-consummatory (of various activities) behaviour, and is often considered 836 to reflect positive affective states. Indeed, safe, comfortable contexts promote rest (e.g. larger

837 home stalls in horses: Raabymagle and Ladewig, 2006). Preferred situations often decrease 838 signs of poor welfare and increase time resting (enriched cages, in rats: Abou-Ismail and 839 Mahboub, 2011; and in mice: Tilly et al., 2010; bedding types that are preferred when the 840 animals are given a choice of stalls in horses: Hunter and Houpt, 1989; Mills et al., 2000; 841 Pedersen et al., 2004; Werhahn et al., 2010). So does providing a more naturalistic social 842 environment in horses by introducing adult conspecifics in groups of sub-adults (Bourjade et 843 al., 2008). Moreover, a variety of stressors, such as chronic exposure to mild unpredictable 844 stressors (rats: Cheeta et al., 1997), exposure to an aggressive dominant conspecific (male 845 tree shrews Tupaia belangeri: Fuchs and Flugge, 2002) and social isolation (rats: Hurst et al., 846 1999), decrease the time the animals spend resting over hours or days. Rats exposed to sleep

847 disturbance (husbandry procedures performed during the non-active light phase) not 848 surprisingly sleep less, spending more time awake non-active and show higher indicators of 849 physiological stress and reduced welfare than do their conspecifics experiencing husbandry 850 procedures during their active dark phase (Abou-Ismail et al., 2008). Moreover, while 851 provoking sexual (positive) interactions during the inactive phase only briefly suppresses 852 sleep in male mice, aversive social conflict induces $12 \mathrm{~h}$ long-lasting sleep disturbances 853 (Meerlo and Turek, 2001). Resting is therefore commonly interpreted as a sign that animals 854 are relaxed and experience positive affective states. 
855 However, in a number of animal studies, resting and sleeping are merged together in the 856 behavioural repertoire, defined by the animal displaying a species-specific posture (usually

857 lying down, but sometimes also sitting or even standing still) with eyes partially or fully 858 closed (e.g. in rats: Hurst et al., 1999; Abou-Ismail et al., 2007; 2008; in rabbits: Zeidner et 859 al., 1983; in birds: Campbell and Tobler, 1984; in horses: Waring, 2003). This is because 860 measuring sleep, a restorative behaviour 'not distinguished by movement' (Carlson, 2012, 861 p289) and which 'can be defined behaviourally by the normal suspension of consciousness 862 and electrophysiologically by specific brain wave criteria' (Purves et al., 2007, p 707) 863 requires performing invasive and/or technically challenging (in animals) measurements, i.e. 864 electroencephalographic (EEG) measurement together with electromyographic (EMG) 865 signals. Following the rationale that the longer a bout of inactivity, the more likely it is to be 866 sleep, some authors have investigated duration of inactivity as a way to estimate sleep in mice

867 (Pack et al., 2007). While inactivity-defined sleep (in that study being motionless for $\geq 40$ s) 868 and EEG-EMG defined sleep did show good convergence in mice (Pack et al., 2007), using 869 such a duration-of-inactivity-only criterion to estimate sleep appears however to be prone to 870 yield false positives. It would not discriminate, for instance, a healthy animal sleeping from 871 an animal awake but inactive due to pain (see part 3). While EEG-EMG therefore appear to 872 remain the 'gold standard' methods to measure sleep, using such techniques is however often 873 too challenging (practically) to perform in most of the farm, zoo and companion animal 874 species, and therefore cannot be applied in a vast number of studies in applied ethology 875 research.

876 Despite (realistically good) reasons to do so, merging sleep and rest in the animals' 877 behavioural repertoire could have significant implications with respect to the welfare states 878 associated to this inactivity. Indeed, in humans, neither sleep quantity nor its quality appear to 
879 be trustworthy indicators of affective states. For instance, insomnia ${ }^{7}$ (APA, 2013) can be 880 caused either by negative feelings such as stress or pain (Purves et al., 2007, p728; Carlson, 881 2012, p298), or by 'excited anticipation of a pleasurable event' (Carlson, 2012, p298). Sleep 882 disturbance is also a prominent symptom of clinical depression (estimated to affect up to $90 \%$ 883 of those with depression, Paterson et al., 2009), but either insomnia or hypersomnia can be 884 observed (e.g. APA, 2013; WHO, 1994; Maurice-Tison et al., 1998; Henn and Vollmayr, 885 2005), with some depressed people even self-reporting mixed insomnia/hypersomnia 886 symptoms (Paterson et al., 2009). Similarly, both insomnia and hypersomnia are part of the 887 diagnostic symptoms under ICD-10 for withdrawal states from stimulants, with people 888 experiencing such states also self-reporting negative emotions such as 'depressed mood', and 889 'decreased contentedness / well-being' (Juliano and Griffiths, 2004). It is also worth noting 890 that sleep manipulations yield quite erratic effects on people's mood. In healthy people, acute 891 and short-term sleep deprivation usually worsens mood (e.g. Weinger and Ancoli-Israel, 892 2002; Drury et al., 2012), but extending sleep (e.g. by 2 or 3 h per night beyond its habitual 893 duration) has been reported to worsen mood, to improve mood or to induce no mood change 894 (David et al., 1991; Ferrara and De Gennaro, 2001). Moreover, while sleep deprivation in 895 healthy people usually worsens mood, it is usually followed by a short-term mood 896 improvement in depressed patients (Benedetti and Colombo, 2011).

897 Thus, while a number of studies in animals do support the view that 'resting' is likely to 898 be associated with positive affective state (enhanced in preferred / positive contexts, reduced 899 in aversive conditions), it seems worth nothing that, in the majority of these studies, the 900 relative proportion of the observed inactivity that is 'simply' resting cannot be disentangled 901 from that 'purely' sleeping due to methodological challenges. As human studies show that 902 sleep is clearly not a trustworthy indicator of the affective state (its duration and quality can

\footnotetext{
7 'subjective complaint of difficulty falling asleep or staying asleep, or poor sleep quality', DSM-V p823
} 
903 be modified in either direction under either positive or negative affective states), the 904 interpretation of the 'resting + sleeping' behaviour in animals in terms of its associated 905 affective state might not be so straightforward.

906

907

908

\section{Further research directions}

909

910

Can inactivity -- in its various forms - be a useful indicator of specific affective states in animals? We think it can, based on analogies with humans self-reporting their feelings while displaying specific forms of inactivity phenotypically similar to those displayed by animals in similar situations (summarised in Table 1). Most of the specific forms we discussed in this 913 paper still need further refinement and validation before they could be used in this way, however.

While some forms are unambiguously specific behaviours (e.g. freezing in rodents, 916 'withdrawn' states in horses) or operationally definable (e.g. with regards to location or other activities such as immediately post-mating) (see column 4 in Table 1), others are less specifically described, such as overall increased inactivity / decreased activity in inactive ill animals or individuals displaying signs of learned helplessness. Reassuringly, contextual information probably favours correct recognition of the associated affective state: an unmedicated animal being inactive post-surgery or displaying signs of ill-health (e.g. fever,

922 injury) is likely to experience the aversive affective component of ill-health conditions, while 923 exposure to inescapable, uncontrollable stressors is unlikely to induce positive feelings. 924 Given such contextual knowledge, inactivity may be useful as an indicator of intensity of the 925 affective state. Effort should nevertheless be made in the future to define these specific forms 926 of inactivity more precisely if relevant to hypothesis under test (e.g. by adding fine postural 927 descriptions) (cf. also 5.4.). 
928

929

930

931

932

933

934

935

936

937

938

939

940

941

942

943

944

945

946

947

948

949

950
Further work could also investigate how those specific forms of inactivity that are currently not pharmacologically validated (see Table 1, last column) would be modulated by giving the animals drugs inducing either negative or positive affective states. This is provided that such drugs have already been validated as inducing the affective state of interest for the tested species, and are known not to induce sedative side effects (risk of circular reasoning otherwise). Such validation would be of primary interest for any forms, but particularly for those few forms observed in animals which are obviously not (food rumination) or not systematically (satiety-induced inactivity) displayed by people, making it difficult in these few cases to use humans-based evidence to infer the associated affective states in animals.

Beyond this, future validation work could investigate to what extent acute stressors and chronically aversive environments increase those specific forms of inactivity believed to reflect negative affective states (with the opposite being the case for preferred environments), to provide a starting point for discriminating between forms of inactivity reflecting shortand/or long-term affective states. It could also investigate the co-variation of a specific form of inactivity with evolutionary fitness (following evolutionary perspectives that predict that individuals are likely to avoid aversive sensations and pursue rewarding sensations that respectively decrease and promote evolutionary fitness, Cabanac, 1971; Fraser and Duncan, 1998); and could investigate whether a specific form of inactivity co-varies with other welfare indicators, provided these are previously-validated indicators of the specific affective state under test (for instance excluding cortisol levels, reported to either increase or decrease in chronically stressed individuals as well as to increase in some positive situations, e.g. in humans: Miller et al., 2007, in animals: Rushen, 1991; Mormede et al., 2007). 
951 Table 1. Specific forms of inactivity and their association with specific affective states. 


\begin{tabular}{|c|c|c|c|c|c|c|c|}
\hline Name & Valence & Arousal & $\begin{array}{l}\text { Specific form of } \\
\text { inactivity, defined } \\
\text { operationally }\end{array}$ & Expressed in response to: & $\begin{array}{l}\text { In humans this } \\
\text { situation (or } \\
\text { similar) has been } \\
\text { reported to be: }\end{array}$ & $\begin{array}{l}\text { Humans display a } \\
\text { phenotypically } \\
\text { similar inactivity: }\end{array}$ & $\begin{array}{l}\text { Pharmacological } \\
\text { evidence? }\end{array}$ \\
\hline Freezing & Negative & High & Yes & $\begin{array}{l}\text { (Perceived) actual or } \\
\text { potential threat }\end{array}$ & Aversive & Yes & $\begin{array}{c}\text { Yes (enhanced by } \\
\text { anxiogenics, reduced } \\
\text { by anxiolytics) }\end{array}$ \\
\hline Tonic immobility & Negative & High & Yes & $\begin{array}{l}\text { (Perceived) actual or } \\
\text { potential threat }\end{array}$ & Aversive & Yes & $\begin{array}{c}\text { Yes (enhanced by } \\
\text { anxiogenics, reduced } \\
\text { by anxiolytics) }\end{array}$ \\
\hline Hiding & Negative & High & $\begin{array}{l}\text { Yes (provided } \\
\text { hiding } \\
\text { opportunities) }\end{array}$ & $\begin{array}{l}\text { (Perceived) actual or } \\
\text { potential threat }\end{array}$ & Aversive & Yes & $\begin{array}{c}\text { Yes (enhanced by } \\
\text { anxiogenics, reduced } \\
\text { by anxiolytics) }\end{array}$ \\
\hline Ill-health inactivity & Negative & Low & $\begin{array}{l}\text { No (decreased } \\
\text { activity) }\end{array}$ & Illness, injury & Aversive & Yes & $\begin{array}{l}\text { Yes (reduced by } \\
\text { analgesics) }\end{array}$ \\
\hline $\begin{array}{lr}\text { Learned } & \text { helplessness } \\
\text { related } & \text { 'floating in } \\
\text { despair' } & \text { (laboratory } \\
\text { rodents) } & \\
\end{array}$ & Negative & $?$ & Yes & Porsolt (forced swim) test & Aversive & $\begin{array}{l}\text { N/A (specific testing } \\
\text { conditions in rodents } \\
\text { are not transferable } \\
\text { to humans) }\end{array}$ & $\begin{array}{l}\text { Yes (reduced by } \\
\text { antidepressants) }\end{array}$ \\
\hline $\begin{array}{l}\text { Learned helplessness } \\
\text { related overall passivity }\end{array}$ & Negative & Low & $\begin{array}{l}\text { No (decreased } \\
\text { activity) }\end{array}$ & $\begin{array}{l}\text { Inescapable / uncontrollable } \\
\text { aversive environments }\end{array}$ & Aversive & Yes & $?$ \\
\hline $\begin{array}{l}\text { Depression-like } \\
\text { 'withdrawn' state (horses) }\end{array}$ & Negative & Low & Yes & $?$ & N/A & $\begin{array}{l}\text { No phenotypically } \\
\text { exactly similar form }\end{array}$ & $?$ \\
\hline $\begin{array}{l}\text { Boredom-like lying down } \\
\text { with eyes open (mink) }\end{array}$ & Negative & $\begin{array}{l}\text { Low (but } \\
\text { debated) }\end{array}$ & Yes & $\begin{array}{l}\text { Barren, impoverished } \\
\text { environments }\end{array}$ & Aversive & $\begin{array}{l}\text { Yes, but restlessness } \\
\text { may also be seen }\end{array}$ & $?$ \\
\hline Standing/lying in the sun & Positive & Low & $\begin{array}{l}\text { Yes (provided } \\
\text { chose shaded / } \\
\text { sunny areas) }\end{array}$ & Sunny area & Positive & Yes & $\begin{array}{l}\text { Yes (induces a } \beta \text { - } \\
\text { endorphin release) }\end{array}$ \\
\hline Post-copulation inactivity & Positive & Low & Yes (timing mating) & Immediately after mating & Positive & Yes & $?$ \\
\hline Satiety-related inactivity & Positive & Low & Yes (timing eating) & Post-prandial & Positive & Unsure & $?$ \\
\hline Rumination (cattle) & Positive & Low & Yes & Post food consumption & $\mathrm{N} / \mathrm{A}$ & $\mathrm{N} / \mathrm{A}$ & $?$ \\
\hline $\begin{array}{l}\text { Stillness when stalking } \\
\text { (cats) }\end{array}$ & Positive & High & Yes & Predation, play & $?$ & $?$ & $?$ \\
\hline
\end{tabular}




\section{Conclusions}

953 Should more attention be paid to inactivity in behavioural and animal welfare studies?

954 Considering subtypes of inactivity, we think it should. First, as discussed in this paper, some

955 specific forms of inactivity (e.g. displayed in response to a perceived threat) are useful 956 indicators of poor welfare states. A number of others forms have, acknowledging that further

957 refinement and validation are still needed, the potential to indicate either negative or positive

958 affective states in animals. This makes additional research into this topic very worthwhile.

959 Moreover, even when inactivity does not result from poor welfare, levels of inactivity that are

960 too high or too low can directly or indirectly induce poorer affective states, raising welfare

961 concerns. For example, in group-housed hens, inactive hens are more likely to be victims of

962 feather pecking, and thus suffer due to high inactivity levels (Riber and Forkman, 2007).

963 Meanwhile, retaining adaptive forms of inactivity is still essential: in reintroduction

964 programmes for endangered species, individuals that have not been active enough to learn

965 appropriate skills before being reintroduced into the wild are likely to have poor welfare once

966 released, since they may be unable to attain sufficient food or find shelter, and may be at

967 higher risk of injury (McPhee, 2004).

968 Using inactivity as an indicator of affective states in animals does require a number of

969 changes in the way we often view inactivity in behavioural and animal welfare studies,

970 however. As discussed throughout this paper, inactivity is not a homogeneous category of

971 behaviour: there are many different, context- (and sometimes species-) specific forms.

972 Merging these specific forms into a single broad category certainly can yield erroneous

973 interpretations with regards to the associated affective states, by e.g. not discriminating a

974 healthy animals resting from an animal inactive due to ill-health conditions. Prior to data

975 collection, ethograms should include precise descriptions (e.g. by adding fine postural

976 descriptions) of any specific form(s) of inactivity relevant to hypotheses under test. A clear 
977 description of which contexts trigger (or conversely, decrease) specific form(s) of inactivity 978 is also crucial, as it is the first, essential, step towards inferring its putatively associated 979 affective state(s). Additional justifications should be provided before inferring putative 980 affective states associated with inactivity in animals. Bringing human and animal studies 981 together to rely on analogies with humans self-reporting their feelings is one of the possible 982 justifications; so are pharmacological approaches, which strengthen construct validity. 983 Further research suggestions mentioned in this paper would certainly deepen our 984 understanding of what inactivity can reveal about affective states in non-human animals, 985 providing new ways of assessing treatment effects and a better understanding of the 986 implications of personality differences.

987

\section{Acknowledgements}

989 We would like to thank Georgia Mason for stimulating discussions about affective states 990 and inactivity and for kindly providing input and feedback on multiple versions of this 991 manuscript; thanks also to Liz Paul, Rachel Casey and Mike Mendl for constructive 992 discussions; and two anonymous referees for their comments on the manuscript. This work 993 was supported by a Fyssen Foundation postdoctoral fellowship (to CF) and a Canada 994 Graduate Scholarship from the Natural Sciences and Engineering Research Council (to RM). 995 The funders had no role in the study design, data collection and analyses, decision to publish 996 or preparation of the manuscript. The authors report no conflicts of interest.

\section{References}

Abou-Ismail, U.A., Burman, O.H.P., Nicol, C.J., Mendl, M., 2007. Can sleep behaviour be 1000 used as an indicator of stress in group-housed rats (Rattus norvegicus)? Anim. Welf. 16, 1001 185-188. 
1002 Abou-Ismail, U.A., Burman, O.H.P., Nicol, C.J., Mendl, M., 2008. Let sleeping rats lie: Does 1003 the timing of husbandry procedures affect laboratory rat behaviour, physiology and $1004 \quad$ welfare? Appl. Anim. Behav. Sci. 111, 329-341.

1005 Abou-Ismail, U.A., Mahboub, H.D., 2011. The effects of enriching laboratory cages using 1006 various physical structures on multiple measures of welfare in singly-housed rats. 1007 Laboratory Animals 45, 145-153.

1008 Abrams, M.P., Carleton, R.N., Taylor, S., Asmundson, G.J.G., 2009. Human tonic 1009 immobility: measurement and correlates. Depress. Anxiety. 26, 550-556.

1010 Abramson, L.Y., Seligman, M.E.P., Teasdale, J.D., 1978. Learned helplessness in humans 1011 critique and reformulation. J. Abnorm. Psychol. 87, 49-74.

1012 American Psychiatric Association, 2013. Diagnostic and Statistical Manual of Mental 1013 Disorders, fifth edition. American Psychiatric Association, Arlington, VA.

1014 Anna, I., Olsson, S., Dahlborn, K., 2002. Improving housing conditions for laboratory mice: a 1015 review of 'environmental enrichment. Laboratory Animals 36, 243-270.

1016 Anonymous, 2005. Oxford English Dictionary. Oxford University Press, Oxford, UK.

1017 Antin, J., Gibbs, J., Holt, J., Young, R.C., Smith, G.P., 1975. Cholecystokinin elicits the 1018 complete behavioral sequence of satiety in rats. J. Comp. Physiol. Psychol. 89, 784-790.

1019 Aubert, A., 1999. Sickness and behaviour in animals: a motivational perspective. Neurosci. $1020 \quad$ Biobehav. Rev. 23, 1029-1036.

1021 Azevedo, T.M., Volchan, E., Imbiriba, L.A., Rodrigues, E.C., Oliveira, J.M., Oliveira, L.F., 1022 Lutterbach, L.G., Vargas, C.D., 2005. A freezing-like posture to pictures of mutilation. 1023 Psychophysiology 42, 255-260.

1024 Baker, M., Dorzab, J., Winokur, G., Cadoret, R.J., 1971. Depressive disease - Classification 1025 and clinical characteristics. Compr. Psychiatry. 12, 354-365. 
1026 Balcombe, J., 2009. Animal pleasure and its moral significance. Appl. Anim. Behav. Sci. $1027 \quad 118,208-216$.

1028 Barratt, E.S., 1965. EEG correlates of tonic immobility in the opossum (Didelphis 1029 virginiana). Electroencephalogr. Clin. Neurophysiol. 18, 709-711.

1030 Bassett, L., Buchanan-Smith, H.M., 2007. Effects of predictability on the welfare of captive $1031 \quad$ animals. Appl. Anim. Behav. Sci. 102, 223-245.

1032 Bateson, P., Young, M., 1981. Separation from the mother and the development of play in 1033 cats. Anim. Behav.29, 173-180.

1034 Beck, A.T., 1967. Depression: Clinical, experimental and theoretical aspects. Harper and 1035 Row, New York.

1036 Benedetti, F., Colombo, C., 2011. Sleep Deprivation in Mood Disorders. $1037 \quad$ Neuropsychobiology 64, 141-151.

1038 Benelam, B., 2009. Satiation, satiety and their effects on eating behaviour. Nutr. Bull. 34, $1039 \quad 126-173$.

1040 Benhajali, H., Richard-Yris, M.A., Leroux, M., Ezzaouia, M., Charfi, F., Hausberger, M., 10412008 . A note on the time budget and social behaviour of densely housed horses - A case 1042 study in Arab breeding mares. Appl. Anim. Behav. Sci. 112, 196-200.

1043 Berlyne, D.E., 1960. Conflict, Arousal, and Curiosity. McGraw-Hill, New York.

1044 Belzung, C., Lemoine, M., 2011. Criteria of validity for animal models of psychiatric 1045 disorders: focus on anxiety disorders and depression. Biology of Mood \& Anxiety 1046 Disorders 2011, 1:9

1047 Bildsoe, M., Heller, K.E., Jeppesen, L.L., 1990. Stereotypies in female ranch: mink seasonal 1048 and diurnal variation. Scientifur 14, 243-248. 
Bildsoe, M., Heller, K.E., Jeppesen, L.L., 1991. Effects of immobility stress and food restriction on stereotypes in low and high stereotyping female ranch mink. Behav. Processes 25, 179-189.

Blackburn-Munro, G., Blackburn-Munro, R.E., 2001. Chronic pain, chronic stress and depression: Coincidence or consequence? J. Neuroendocrinol. 13, 1009-1023.

Blanchard, D.C., Griebel, G., Pobbe, R., Blanchard, R.J., 2011. Risk assessment as an evolved threat detection and analysis process. Neurosci. Biobehav. Rev. 35, 991-998.

Blanchard, D.C., Hynd, A.L., Minke, K.A., Minemoto, T., Blanchard, R.J., 2001. Human defensive behaviors to threat scenarios show parallels to fear- and anxiety-related defense patterns of non-human mammals. Neurosci. Biobehav. Rev. 25, 761-770.

Boelsma, E., Brink, E.J., Stafleu, A., Hendriks, H.F.J., 2010. Measures of postprandial wellness after single intake of two protein-carbohydrate meals. Appetite 54, 456-464.

Boissy, A., 1995. Fear and fearfulness in animals. Q. Rev. Biol. 70, 165-191.

Bosch, G., Beerda, B., van de Hoek, E., Hesta, M., van der Poel, A.F.B., Janssens, G.P.J., Hendriks, W.H., 2009. Effect of dietary fibre type on physical activity and behaviour in kennelled dogs. Appl. Anim. Behav. Sci. 121, 32-41.

Bourjade, M., Moulinot, M., Richard-Yris, M.A., Hausberger, M., 2008. Could adults be used to improve social skills of young horses, Equus caballus? Dev. Psychobiol. 50, 408-417.

Bouton, M.E., Bolles, R.C., 1980. Conditioned fear assessed by freezing and by the suppression of 3 different baselines. Anim. Learn. Behav. 8, 429-434.

Boys, A., Marsden, J., Strang, J., 2001. Understanding reasons for drug use amongst young people: a functional perspective. Health Educ. Res. 16, 457.

Bracha, H.S., 2004. Freeze, flight, fight, fright, faint: Adaptationist perspectives on the acute stress response spectrum. Cns Spectrums 9, 679-685. 
1073 Braud, W.G., Ginsburg, H.J., 1973. Effect of administration of adrenaline on immobility 1074 reaction in domestic fowl. J. Comp. Physiol. Psychol. 83, 124-127.

1075 Bristow, D.J., Holmes, D.S., 2007. Cortisol levels and anxiety-related behaviors in cattle. 1076 Physiol. Behav.90, 626-628.

1077 Broom, D.M., 1988. The scientific assessment of animal-welfare. Appl. Anim. Behav. Sci. $1078 \quad 20,5-19$.

1079 Brune, M., Brune-Cohrs, U., McGrew, W.C., Preuschoft, S., 2006. Psychopathology in great 1080 apes: Concepts, treatment options and possible homologies to human psychiatric 1081 disorders. Neurosci. Biobehav. Rev. 30, 1246-1259.

1082 Burrell, A.M., Altman, J.D., 2006. The effect of the captive environment on activity of 1083 captive cotton-top tamarins (Saguinus oedipus). J Appl. Anim. Welf. Sci. 9(4), 269-276.

1084 Byrne, A., Byrne, D.G., 1993. The effect of exercise on depression, anxiety and other mood 1085 states - a review. J. Psychosom. Res. 37, 565-574.

1086 Cabanac, M., 1971. Physiological role of pleasure. Science 173, 1103-1107.

1087 Cahn, B.R., Polich, J., 2006. Meditation states and traits: EEG, ERP, and neuroimaging $1088 \quad$ studies. Psychol Bull. 132, 180-211.

1089 Calderon, D.F., Cook, N.B., 2011. The effect of lameness on the resting behavior and 1090 metabolic status of dairy cattle during the transition period in a freestall-housed dairy herd. 1091 J. Dairy Sci. 94, 2883-2894.

1092 Campbell, S.S., 1992. The Timing and Structure of Spontaneaus Naps, in: Stampi, C. (Ed.), 1093 Why we nap: evolution, chronobiology, and functions of polyphasic and ultrashort sleep, 1094 Birkhauser, Boston, USA, pp. 71-81.

1095 Campbell, S.S., Tobler, I., 1984. Animal sleep - A review of sleep duration across phylogeny. 1096 Neurosci. Biobehav. Rev. 8, 269-300. 
1097 Camus, S.M.J., Rochais, C., Blois-Heulin, C., Li, Q., Hausberger, M., Bezard, E., 2013. Birth 1098 origin differentially affects depressive- like behaviours: are captive- born cynomolgus 1099 monkeys more vulnerable to depression than their wild- born counterparts? PloS one 8, $1100 \quad$ e67711.

1101 Carlson, N.R., 2012. Physiology of Behavior 11th Edition. Pearson Education Inc., Boston, 1102 USA.

1103 Carlstead, K., 1996. Effects of captivity on the behavior of wild mammals in: Kleiman, D.G., 1104 Allen, M.E., Thompson, K.V., Lumpkin, S. (Eds.), Wild Mammals in Captivity, 1105 University of Chicago Press, Chicago,pp. 317-333.

1106 Carlstead, K., Brown, J.L., Seidensticker, J., 1993a. Behavioral and adrenocortical responses 1107 to environmental-changes in leopard cats (Felis bengalensis). Zoo Biol. 12, 321-331.

1108 Carlstead, K., Brown, J.L., Strawn, W., 1993b. Behavioral and physiological correlates of 1109 stress in laboratory cats. Appl. Anim. Behav. Sci. 38, 143-158.

1110 Celli, M.L., Tomonaga, M., Udono, T., Teramoto, M., Nagano, K., 2003. Tool use task as 1111 environmental enrichment for captive chimpanzees. Appl. Anim. Behav. Sci. 81, 171-182.

1112 Chapinal, N., de Passille, A.M., Rushen, J., Wagner, S., 2010. Automated methods for 1113 detecting lameness and measuring analgesia in dairy cattle. J. Dairy Sci. 93, 2007-2013.

1114 Cheeta, S., Ruigt, G., vanProosdij, J., Willner, P., 1997. Changes in sleep architecture 1115 following chronic mild stress. Biol. Psychiatry 41, 419-427.

1116 Chourbaji, S., Zacher, C., Sanchis-Segura, C., Spanagel, R., Gass, P., 2005. Social and 1117 structural housing conditions influence the development of a depressive-like phenotype in 1118 the learned helplessness paradigm in male mice. Behav. Brain Res. 164, 100-106.

1119 Clark, S.L.L., F.H.Cutler,J.T., 1939. A form of congenital myotonia in goats. J. Nerv. Ment. 1120 Dis. $90,297-309$. 
Cockram, M.S., 2004. A review of behavioural and physiological responses of sheep to stressors to identify potential behavioural signs of distress. Anim. Welf. 13, 283-291.

Cronbach, L.J., Meehl, P.E., 1955. Construct validity in psychological tests. Psychol. Bull. $52,281-302$.

Cooper, J.J., Odberg, F., Nicol, C.J., 1996. Limitations on the effectiveness of environmental improvement in reducing stereotypic behaviour in bank voles (Clethrionomys glareolus). Appl. Anim. Behav. Sci. 48, 237-248.

Correia, A.D., Cunha, S.R., Scholze, M., Stevens, E.D., 2011. A Novel Behavioral Fish Model of Nociception for Testing Analgesics. Pharmaceuticals 4, 665-680.

Crawford, K.M., Spotila, J.R., Standora, E.A., 1983. Operative environmental temperatures and basking behavior of the turtle Pseudemys scripta. Ecology 64, 989-999.

Crawley, J.N., Hays, S.E., Paul, S.M., Goodwin, F.K., 1981. Cholecystokinin reduces exploratory-behavior in mice. Physiol. Behav.27, 407-411.

Crawley, J.N., Rojasramirez, J.A., Mendelson, W.B., 1982. The role of central and peripheral cholecystokinin in mediating appetitive behaviors. Peptides 3, 535-538.

Cryan, J.F., Markou, A., Lucki, I., 2002. Assessing antidepressant activity in rodents: recent developments and future needs. Trends Pharmacol. Sci. 23, 238-245.

Csikszentmihalyi, M., 1975. Beyond Boredom and Anxiety: Experiencing Flow in Work and Play. Jossey-Bass, San Francisco.

Csikszentmihalyi, M., 1990. Flow: The psychology of optimal experience. Harper \& Row, New York.

Dallaire, J.A., Meagher, R.K., Mason, G.J., 2012. Individual differences in stereotypic behaviour predict individual differences in the nature and degree of enrichment use in caged American mink. Appl. Anim. Behav. Sci. 142, 98-108. 
1145

1146

1147

1148

1149

1150

1151

1152

1153

1154

1155

1156

1157

1158

1159

1160

1161

1162

1163

1164

1165

1166

1167

1168

Dalm, S., de Visser, L., Spruijt, B.M., Oitzl, M.S., 2009. Repeated rat exposure inhibits the circadian activity patterns of C57BL/6J mice in the home cage. Behav. Brain Res. 196, 8492.

Dantzer, R., 2004. Cytokine-induced sickness behaviour: a neuroimmune response to activation of innate immunity. Eur. J. Pharmacol. 500, 399-411.

David, M.M., Maclean, A.W., Knowles, J.B., Coulter, M.E., 1991. Rapid eye-movement latency and mood following a delay of bedtime in healthy-subjects: do the effects mimic changes in depressive-illness? Acta Psychiatr. Scand. 84, 33-39.

Davis, K., Dimidjian, S., 2012. The Relationship Between Physical Activity and Mood Across the Perinatal Period: A Review of Naturalistic and Clinical Research to Guide Future Investigation of Physical Activity-Based Interventions for Perinatal Depression. Clin. Psychol. Science and Practice 19, 27-48.

Dawkins, M.S., 1988. Behavioral deprivation - A central problem in animal-welfare. Appl. Anim. Behav. Sci. 20, 209-225.

De Passillé, A.M.B., Christopherson, R., Rushen, J., 1993. Nonnutritive sucking by the calf and postprandial secretion of insulin, CCK, and gastrin. Physiol. Behav.54, 1069-1073.

DeMonte, M., LePape, G., 1997. Behavioural effects of cage enrichment in single-caged adult cats. Anim. Welf. 6, 53-66.

Deussing, J.M., 2006. Animal models of depression. Drug discovery today: disease models 3, $375-383$.

DeVries, T.J., Beauchemin, K.A., Dohme, F., Schwartzkopf-Genswein, K.S., 2009. Repeated ruminal acidosis challenges in lactating dairy cows at high and low risk for developing acidosis: Feeding, ruminating, and lying behavior. J. Dairy Sci. 92, 5067-5078.

Dhaenen, H., 1996. Measurement of anhedonia. Eur. Psychiatry 11, 335-343. 
1169 Dielenberg, R.A., McGregor, I.S., 1999. Habituation of the hiding response to cat odor in rats $1170 \quad$ (Rattus norvegicus). J Comp. Psychol.113, 376-387.

1171 Dixson, A., 2010. Homosexual behaviour in primates, in: Poiani, A. (Ed.), Animal 1172 homosexuality - a biosocial perspective, University Press, Cambridge, pp. 381-399.

1173 Downs, C.T., Greaver, C., Taylor, R., 2008. Body temperature and basking behaviour of Nile 1174 crocodiles (Crocodylus niloticus) during winter. J. Therm. Biol. 33, 185-192.

1175 Drury, D.A., Ferguson, S.A., Thomas, M.J.W., 2012. Restricted sleep and negative affective 1176 states in commercial pilots during short haul operations. Accid. Anal. Prev. 45, 80-84.

1177 Duncan, I.J.H. 2005. Science-based assessment of animal welfare: farm animals. Rev. Sci. 1178 Tech. Off. Int. Epiz. 24, 483-492.

1179 Duncan, I.J.H., 1970. Frustration in the fowl, in: Freeman, B.M., Gordon, R.F. (Eds.), 1180 Aspects of Poultry Behaviour, Edinburgh, UK, British Poultry Science Ltd., pp. 15-31.

1181 Dunn, A.L., Trivedi, M.H., O'Neal, H.A., 2001. Physical activity dose-response effects on 1182 outcomes of depression and anxiety. Med. Sci. Sports Exerc. 33, S587-S597.

1183 Eastwood, J.D., Frischen, A., Fenske, M.J., Smilek, D., 2012. The Unengaged Mind. $1184 \quad$ Perspect. Psychol. Sci. 7, 482-495.

1185 Engel, C., 2002. Wild health - How animals keep themselves well and what we can learn 1186 from them. Weidenfeld and Nicolson, London.

1187 Engel, G.L., Schmale, A.H., 1972. Conservation-withdrawal: a primary regulatory process 1188 for organismic homeostasis, in: Elsevier (Ed.), Physiology, Emotion and Psychosomatic 1189 Illness, New York, pp. 57-75.

1190 Espejo, L.A., Endres, M.I., 2007. Herd-level risk factors for lameness in high-producing 1191 Holstein cows housed in freestall barns. J. Dairy Sci. 90, 306-314. 
1192

1193

1194

1195

1196

1197

1198

1199

1200

1201

1202

1203

1204

1205

1206

1207

1208

1209

1210

1211

1212

1213

1214

1215

Espmark, Y., Langvatn, R., 1985. Development and habituation of cardiac and behavioralresponses in young red deer calves (cervus-elaphus) exposed to alarm stimuli. J. Mammal. $66,702-711$

Facchinetti, L.D., Imbiriba, L.A., Azevedo, T.M., Vargas, C.D., Volchan, E., 2006. Postural modulation induced by pictures depicting prosocial or dangerous contexts. Neurosci. Lett. $410,52-56$.

Falasco, J.D., Smith, G.P., Gibbs, J., 1979. Cholecystokinin suppresses sham feeding in the rhesus-monkey. Physiol. Behav.23, 887-890.

Fanselow, M.S., 1982. The postshock activity burst. Anim. Learn. Behav. 10, 448-454.

Fanselow, M.S., 1984. What is conditioned fear? Trends Neurosci. 7, 460-462.

Fanselow, M.S., Helmstetter, F.J., 1988. Conditional analgesia, defensive freezing and benzodiazepines. Behav. Neurosci. 102, 233-243.

Farook, J.M., McLachlan, C.S., Zhu, Y.Z., Lee, L., Moochhala, S.M., Wong, P.T.H., 2004. The CCK2 agonist BC264 reverses freezing behavior habituation in PVG hooded rats on repeated exposures to a cat. Neurosci. Lett. 355, 205-208.

Faure, J.M., Guemene, D., Guy, G., 2001. Is there avoidance of the force feeding procedure in ducks and geese? Anim. Res. 50, 157-164.

Fell, G.L., Robinson, K.C., Mao, J., Woolf, C.J., Fisher, D.E., 2014. Skin $\beta$-Endorphin Mediates Addiction to UV Light. Cell 157, 1527-1534.

Ferdowsian, H.R., Durham, D.L., Kimwele, C., Kranendonk, G., Otali, E., Akugizibwe, T., Mulcahy, J.B., Ajarova, L., Johnson, C.M., 2011. Signs of Mood and Anxiety Disorders in Chimpanzees. Plos One 6, e19855.

Ferrara, M., De Gennaro, L., 2001. How much sleep do we need? Sleep Med. Rev. 5, 155179. 
1216 Fiske, D.W., Maddi, S.R., 1961. Functions of varied experience / [edited by] Donald W. 1217 Fiske and Salvatore R. Maddi ; with contributions by James Bieri. Homewood,Ill. : 1218 Dorsey, Homewood,Ill.

1219 Fordham, D.P., Algahtani, S., Durotoye, L.A., Rodway, R.G., 1991. Changes in plasma1220 cortisol and beta-endorphin concentrations and behavior in sheep subjected to a change of environment. Anim. Production 52, 287-296.

1222

Forkman, B., Boissy, A., Meunier-Salauen, M.C., Canali, E., Jones, R.B., 2007. A critical review of fear tests used on cattle, pigs, sheep, poultry and horses. Physiol. Behav. 92, $340-374$

1225

Fox, M.W., 1968. Abnormal behavior in animals. W.B. Saunders Company, Philadelphia.

Fraser, D., 2008. Understanding animal welfare: the science in its cultural context. WileyBlackwell, Oxford. 324 pages

Fraser, D., Duncan, I.J.H., 1998. 'Pleasures','pains' and animal welfare: Toward a natural

1230 Fuchs, E., Flugge, G., 2002. Social stress in tree shrews: Effects on physiology, brain 1231 function, and behavior of subordinate individuals. Pharmacol. Biochem. Behav. 73, 2471232258.

1233 Fureix, C., Beaulieu, C., Argaud, S., Rochais, C., Quinton, M., Henry, S., Hausberger, M., 1234 Mason, G., 2015. Investigating anhedonia in a non-conventional species: do some riding 1235 horses Equus caballus display symptoms of depression? Appl. Anim. Behav. Sci. 162, 26123636.

1237 Fureix, C., Jego, P., Henry, S., Lansade, L., Hausberger, M., 2012. Towards an Ethological 1238 Animal Model of Depression? A Study on Horses. Plos One 7, e39280. 
1239 Galliano, G., Noble, L.M., Travis, L.A., Puechl, C., 1993. Victim reactions during 1240 rape/sexual assault - A preliminary study of the immobility response and its correlates. J. $1241 \quad$ Interpers. Violence. 8, 109-114.

1242 Gallup, G.G., 1973. Tonic immobility in chickens - Is a stimulus that signals shock more 1243 aversive than receipt of shock. Anim. Learn. Behav. 1, 228-232.

1244 Gallup, G.G., 1974. Animal hypnosis: Factual status of a fictional concept. Psychol. Bull. 81, $1245 \quad 836-853$.

1246 Gallup, G.G., Nash, R.F., Brown, C.W., 1971a. The effects of a tranquilizer on immobility 1247 reaction in chickens - Additional support for fear hypothesis. Psychon. Sci. 23, 127-128.

1248 Gallup, G.G., Nash, R.F., Potter, R.J., Donegan, N.H., 1970. Effect of varying conditions of 1249 fear on immobility reactions in domestic chickens (Gallus gallus). J. Comp. Physiol. $1250 \quad$ Psychol. 73, 442-445.

1251 Gallup, G.G., Nash, R.F., Wagner, A.M., 1971b. Tonic immobility reaction in chickens 1252 Response characteristics and methodology. Behavior Research Methods \& 1253 Instrumentation 3, 237-239.

1254 Gallup, G.G., Williamson, G.T., 1972. Effect of food deprivation and a visual cliff on tonic 1255

Garrick, L.D., 1979. Lizard Thermoregulation: Operant Responses for Heat at Different 1257 Thermal Intensities. Copeia 2, 258-266.

1258 Gilman, T.T., Marcuse, F.L., Moore, A.U., 1950. Animal hypnosis - A study in the induction 1259 of tonic immobility in chickens. J. Comp. Physiol. Psychol. 43, 99-111.

1260 Goats, G.C., 1994. Massage--the scientific basis of an ancient art: part 2. physiological and 1261 therapeutic effects. Br. J. Sports Med. 28, 153.

1262 Gotlib, I.H., Krasnoperova, E., 1998. Biased information processing as a vulnerability factor 1263 for depression. Behav. Ther. 29, 603-617. 
1264 Graber, B., Rohrbaugh, J.W., Newlin, D.B., Varner, J.L., Ellingson, R.J., 1985. EEG during masturbation and ejaculation. Arch. Sex. Behav. 14, 491-503.

Groothuis, T. G. G. \& Carere, C. 2005. Avian personalities: characterization and epigenesis. Neuroscience and biobehavioral reviews, 29, 137-150.

Hammen, C., Kim, E.Y., Eberhart, N.K., Brennan, P.A., 2009. Chronic and acute stress and 1269 the prediction of major depression in women. Depress. Anxiety. 26, 718-723.

1270

Hansen, S.W., Moller, S.H., 2008. Diurnal activity patterns of farm mink (Mustela vison) subjected to different feeding routines. Appl. Anim. Behav. Sci. 111, 146-157.

1272

Harlow, H., Suomi, S., 1974. Induced Depression in Monkeys. Behav. Biol. 12, 273-296.

1273

Harlow, H.F., Harlow, M.K., 1962. Social deprivation in monkeys. Sci. Am. 207, 136-146.

1274

Harris, M.B., 2000. Correlates and characteristics of boredom proneness and boredom. J. Appl. Soc. Psychol. 30, 576-598.

1276

Harrold, J.A., Doyey, T.M., Blundell, J.E., Halford, J.C.G., 2012. CNS regulation of appetite. Neuropharmacology 63, 3-17.

Hart, B.L., 1988. Biological basis of the behavior of sick animals. Neurosci. Biobehav. Rev. 1279 $12,123-137$.

1280

1281

1282

Heaman, M., Gupton, A., 1998. Perceptions of bed rest by women with high-risk

Heiderstadt, K.M., McLaughiin, R.M., Wright, D.C., Walker, S.E., Gomez-Sanchez, C.E., pregnancies: A comparison between home and hospital. Birth-Issues in Perinatal Care 25, 252-258.

1285 2000. The effect of chronic food and water restriction on open-field behaviour and serum corticosterone levels in rats. Lab. Anim. 34, 20-28.

1286

Henn, F.A., Vollmayr, B., 2005. Stress models of depression: Forming genetically vulnerable 1287 strains. Neurosci. Biobehav. Rev. 29, 799-804. 
Hennessy, M.B., McCowan, B., Jiang, J., Capitanio, J.P., 2014. Depressive-like behavioral response of adult male rhesus monkeys during routine animal husbandry procedure. Frontiers in Behav. Neurosci. 8, 309.

Hogan, L.A., Johnston, S.D., Lisle, A., Horsup, A.B., Janssen, T., Phillips, C.J.C., 2010. Stereotypies and environmental enrichment in captive southern hairy-nosed wombats, Lasiorhinus latifrons. Appl. Anim. Behav. Sci. 126, 85-95.

Hopwood, N., Maswanganyi, T., Harden, L.M., 2009. Comparison of anorexia, lethargy, and fever induced by bacterial and viral mimetics in rats. Can. J. Physiol. Pharmacol. 87, 211220.

Hughes, S.M., Kruger, D.J., 2011. Sex Differences in Post-Coital Behaviors in Long- and Short-Term Mating: An Evolutionary Perspective. J. Sex. Res. 48, 496-505.

Hunter, L., Houpt, K.A., 1989. Bedding material preferences of ponies. J. Anim. Sci. 67, 1986-1991.

Hurst, J.L., Barnard, C.J., Tolladay, U., Nevison, C.M., West, C.D., 1999. Housing and welfare in laboratory rats: effects of cage stocking density and behavioural predictors of welfare. Anim. Behav.58, 563-586.

Inglis, I.R., 1983. Towards a cognitive theory of exploratory behavior, in: Archer, J., Birke, L.I.A. (Eds.), Exploration in animals and man, Van Nostrand Reinhold, London, UK, pp. 72-115.

Jones, M.A., Mason, G.J., Pillay, N., 2011. Correlates of birth origin effects on the development of stereotypic behaviour in striped mice, Rhabdomys. Anim. Behav.82, 149159.

Jones, R.B., 1992. The nature of handling immediately prior to test affects tonic immobility fear reactions in laying hens and broilers. Appl. Anim. Behav. Sci. 34, 247-254. 
1312

1313

1314

1315

1316

1317

1318

Jones, R.B., Beuving, G., Blokhuis, H.J., 1988. Tonic immobility and heterophil lymphocyte responses of the domestic fowl to corticosterone infusion. Physiol. Behav.42, 249-253.

Juliano, L.M., Griffiths, R.R., 2004. A critical review of caffeine withdrawal: empirical validation of symptoms and signs, incidence, severity, and associated features. Psychopharmacology 176, 1-29.

Kilgour, R.J., 2012. In pursuit of "normal": A review of the behaviour of cattle at pasture. Appl. Anim. Behav. Sci. 138, 1-11.

Kirkden, R.D., 2000. Assessing motivational strength and studies of boredom and enrichment in pigs, University of Cambridge.

Klemm, W.R., 1966. Electroencephalographic-behavioral dissociations during animal hypnosis. Electroencephalogr. Clin. Neurophysiol. 21, 365.

Knowles, R.D., 1981. Coping with lethargy. Am. J. Nurs. 81, 1465-1465.

Knox, D., Fitzpatrick, C.J., George, S.A., Abelson, J.L., Liberzon, I., 2012. Unconditioned freezing is enhanced in an appetitive context: Implications for the contextual dependency of unconditioned fear. Neurobiol. Learn. Mem. 97, 386-392.

Koistinen, T., Turunen, A., Kiviniemi, V., Ahola, L., Mononen, J., 2009. Bones as enrichment for farmed blue foxes (Vulpes lagopus): Interaction with the bones and preference for a cage with the bones. Appl. Anim. Behav. Sci. 120, 108-116.

Konrad, K., W., Bagshaw, M., 1970. Effect of novel stimuli on cats reared in a restricted environment. J. Comp. Physiol. Psychol. 70, 157-164.

Kortner, G., Geiser, F., 1999. Roosting behaviour of the tawny frogmouth (Padargus strigoides). J. Zool. 248, 501-507.

Kry, K., Casey, R., 2007. The effect of hiding enrichment on stress levels and behaviour of domestic cats (Felis sylvestris catus) in a shelter setting and the implications for adoption potential. Anim. Welf. 16, 375-383. 
Leach, M.C., Allweiler, S., Richardson, C., Roughan, J.V., Narbe, R., Flecknell, P.A., 2009. Behavioural effects of ovariohysterectomy and oral administration of meloxicam in laboratory housed rabbits. Res. Vet. Sci. 87, 336-347.

1340 Leach, M.C., Klaus, K., Miller, A.L., di Perrotolo, M.S., Sotocinal, S.G., Flecknell, P.A., 1341 2012. The Assessment of Post-Vasectomy Pain in Mice Using Behaviour and the Mouse 1342 Grimace Scale. Plos One 7(4), e35656.

1343 Leaton, R.N., Borszcz, G.S., 1985. Potentiated startle - Its relation to freezing and shock 1344 intensity in rats. J. Exp. Psychol. - Anim. Behav. Processes. 11, 421-428.

1345 Leslie, E., Hernandez-Jover, M., Newman, R., Holyoake, P., 2010. Assessment of acute pain 1346 experienced by piglets from ear tagging, ear notching and intraperitoneal injectable 1347 transponders. Appl. Anim. Behav. Sci. 127, 86-95.

1348 Levin, R.J., 2007. Sexual activity, health and well-being: the beneficial roles of coitus and 1349 masturbation. Sex. Relation. Ther. 22, 135-148.

1350 Levitis, D.A., Lidicker, J.Z., Freund, G., 2009. Behavioural biologists do not agree on what 1351 constitutes behaviour. Anim. Behav.78, 103-110.

1352

Lima, S.L., Rattenborg, N.C., Lesku, J.A., Amlaner, C.J., 2005. Sleeping under the risk of 1353 predation. Anim. Behav.70, 723-736.

1354 Lindwall, M., Larsman, P., Hagger, M.S., 2011. The Reciprocal Relationship Between 1355 Physical Activity and Depression in Older European Adults: A Prospective Cross-Lagged Panel Design Using SHARE Data. Health Psychol. 30, 453-462.

Loas, G., Noisette, C., Legrand, A., Boyer, P., 2000. Is anhedonia a specific dimension in 1358 chronic schizophrenia? Schizophr. Bull. 26, 495-506.

1359

Lopes, F.L., Azevedo, T.M., Imbiriba, L.A., Freire, R.C., Valenca, A.M., Caldirola, D., 1360 Perna, G., Volchan, E., Nardi, A.E., 2009. Freezing reaction in panic disorder patients 1361 associated with anticipatory anxiety. Depress. Anxiety. 26, 917-921. 
1362 Louvart, N., Maccari, S., Ducrocq, F., Thomas, P., Darnaudery, M., 2005. Long-term 1363 behavioural alterations in female rats after a single intense footshock followed by 1364 situational reminders. Psychoneuroendocrinology 30, 316-324.

1365 Lush, J.L., 1930. "Nervous" goats. J. Hered. 21, 243-247.

1366 Luyten, L., Vansteenwegen, D., van Kuyck, K., Nuttin, B., 2011. Towards chronic contextual 1367 conditioning in rats: The effects of different numbers of unpaired tone-shock presentations 1368 on freezing time and startle. Acta Neurobiol. Exp. 71, 331-338.

1369 Maes, M., Berk, M., Goehler, L., Song, C., Anderson, G., Galecki, P., Leonard, B., 2012. 1370 Depression and sickness behavior are Janus-faced responses to shared inflammatory $1371 \quad$ pathways. Bmc Med. 10, 19.

1372 Maier, S.F., 1984. Learned helplessness and animal-models of depression. Prog. 1373 Neuropsychopharmacol. Biol. Psychiatry. 8, 435-446.

1374 Maier, S.F., Seligman, M.E.P., 1976. Learned helplessness - Theory and evidence. J. Exp. 1375 Psychol. Gen. 105, 3-46.

1376 Marais, M., Maloneya, S.K., Graya, D.A., 2013. Sickness behaviours in ducks include 1377 anorexia but not lethargy. Appl. Anim. Behav. Sci. 145, 102-108.

1378 Maren, S., Fanselow, M.S., 1998. Appetitive motivational states differ in their ability to 1379 augment aversive fear conditioning in rats (Rattus norvegicus). J. Exp. Psychol. Anim. 1380 Behav. Processes. 24, 369-373.

1381 Marin, R.S., Wilkosz, P.A., 2005. Disorders of diminished motivation. J. Head. Trauma. $1382 \quad$ Rehabil. 20(4), 377-88.

1383 Maslach, C., Schaufeli, W.B., Leiter, M.P., 2001. Job burnout. Annu. Rev. Psychol. 52, 397$1384 \quad 422$.

1385 Mason, G.J., Latham, N.R., 2004. Can't stop, won't stop: is stereotypy a reliable animal 1386 welfare indicator? Anim. Welf. 13, 57-69. 
Mason, G.J., Veasey, J.S., 2010. How should the psychological well- being of zoo elephants be objectively investigated? Zoo Biol. 29, 237-255.

1389

Matthews, K., Christmas, D., Swan, J., Sorrell, E., 2005. Animal models of depression: navigating through the clinical fog. Neurosci. Biobehav. Rev. 29, 503-513.

Maurice-Tison, S., Verdoux, H., Gay, B., Perez, P., Salamon, R., Bourgeois, M.L., 1998. How to improve recognition and diagnosis of depressive syndromes using international diagnostic criteria. Br. J. Gen. Pract. 48, 1245-1246.

1394

McArthur, R., Borsini, F., 2006. Animal models of depression in drug discovery: A historical perspective. Pharmacol. Biochem. Behav. 84, 436-452.

1396

McFarland, D., 1989. Longman Scientific \& Technical, Wiley, Harlow Essex New York.

1397

McGrath, P.J., Rosmus, C., Canfield, C., Campbell, M.A., Hennigar, A., 1998. Behaviours caregivers use to determine pain in non-verbal, cognitively impaired individuals. Dev. Med. Child. Neurol. 40, 340-343.

McPhee, M.E., 2004. Generations in captivity increases behavioral variance: considerations for captive breeding and reintroduction programs. Biol. Conserv. 115, 71-77.

McPhee, M.E., Carlstead, K., 2010. The Importance of Maintaining Natural Behaviors in 1403 Captive Mammals, in: Kleiman, D.G., Thompson, K.V., Baer, C.K. (Eds.), Wild 1404 Mammals in Captivity, Principles and techniques for zoo management, second edition, 1405 University of Chicago Press, Chicago, pp. 303-313.

1406 Meagher, R.K., Campbell, D.L.M., Dallaire, J.A., Diez-Leon, M., Palme, R., Mason, G.J., 1407 2013. Sleeping tight or hiding in fright? The welfare implications of different subtypes of 1408 inactivity in mink. Appl. Anim. Behav. Sci. 144, 138-146.

1409 Meagher, R.K., Mason, G.J., 2012. Environmental Enrichment Reduces Signs of Boredom in $1410 \quad$ Caged Mink. Plos One 7(11), e49180. 
1411

1412

1413

1414

1415

1416

1417

1418

1419

1420

1421

1422

1423

1424

1425

1426

1427

1428

1429

1430

1431

1432

1433

Meerlo, P., DeBoer, S.F., Koolhaas, J.M., Daan, S., VandenHoofdakker, R.H., 1996a. Changes in daily rhythms of body temperature and activity after a single social defeat in rats. Physiol. Behav.59, 735-739.

Meerlo, P., Overkamp, G.J.F., Benning, M.A., Koolhaas, J.M., vandenHoofdakker, R.H., 1996b. Long-term changes in open field behaviour following a single social defeat in rats can be reversed by sleep deprivation. Physiol. Behav.60, 115-119.

Meerlo, P., Turek, F.W., 2001. Effects of social stimuli on sleep in mice: non-rapid-eyemovement (NREM) sleep is promoted by aggressive interaction but not by sexual interaction. Brain Res. 907, 84-92.

Mendl, M., Burman, O.H.P., Paul, E.S., 2010. An integrative and functional framework for the study of animal emotion and mood. Proc. Biol. Sci. B. 277, 2895-2904.

Mewaldt, L.R., Rose, R.G., 1960. Orientation of migratory restlessness in the white-crowned sparrow. Science 131, 105-106.

Michel, G., Carton, S., Jouvent, R., 1997. Sensation seeking and anhedonia in risk taking behaviors. Study in bungee jumpers. Enceph.-Rev. Psychiatr. Clin. Biol. Ther. 23, 403411.

Mikulas, W.L., Vodanovich, S.J., 1993. The essence of boredom. Psychol. Rec. 43, 3-12.

Miller, G.E., Chen, E., Zhou, E.S., 2007. If it goes up, must it come down? Chronic stress and the hypothalamic-pituitary-adrenocortical axis in humans. Psychol Bull. 133, 25-45.

Mills, D.S., Eckley, S., Cooper, J.J., 2000. Thoroughbred bedding preferences, associated behaviour differences and their implications for equine welfare. Anim. Sci. 70, 95-106.

Mineka, S., Hendersen, R.W., 1985. Controllability and predictability in acquired motivation. Annu. Rev. Psychol. 36, 495-529. 
1434 Mongeluzi, D.L., Rosellini, R.A., Ley, R., Caldarone, B.J., Stock, H.S., 2003. The 1435 conditioning of dyspneic suffocation fear - Effects of carbon dioxide concentration on 1436 behavioral freezing and analgesia. Behav. Modif. 27, 620-636.

1437 Mormede, P., Andanson, S., Auperin, B., Beerda, B., Guemene, D., Malnikvist, J., Manteca, 1438 X., Manteuffel, G., Prunet, P., van Reenen, C.G., Richard, S., Veissier, I., 2007. 1439 Exploration of the hypothalamic-pituitary-adrenal function as a tool to evaluate animal $1440 \quad$ welfare. Physiol. Behav.92, 317-339.

1441 Muhsen, K., Garty-Sandalon, N., Gross, R., Green, M.S., 2010. Psychological distress is 1442 independently associated with physical inactivity in Israeli adults. Preventive Med. 50, $1443 \quad 118-122$.

1444 Nash, R.F., Gallup, G.G., Czech, D.A., 1976. Psychophysiological correlates of tonic 1445 immobility in domestic chicken (Gallus gallus). Physiol. Behav.17, 413-418.

1446 Nimon, A.J., Broom, D.M., 1999. The welfare of farmed mink (Mustela vison) in relation to 1447 housing and management: A review. Anim. Welf. 8, 205-228.

1448 Nowak, R., 2006. Suckling, Milk, and the Development of Preferences Toward Maternal 1449 Cues by Neonates: From Early Learning to Filial Attachment? Adv. Study. Behav. 36, 1$1450 \quad 58$

1451 O'Callaghan, K.A., Cripps, P.J., Downham, D.Y., Murray, R.D., 2003. Subjective and 1452 objective assessment of pain and discomfort due to lameness in dairy cattle. Anim. Welf. $1453 \quad 12,605-610$.

1454 Offinger, J., Herdtweck, S., Rizk, A., Starke, A., Heppelmann, M., Meyer, H., Janssen, S., 1455 Beyerbach, M., Rehage, J., 2013. Postoperative analgesic efficacy of meloxicam in lame 1456 dairy cows undergoing resection of the distal interphalangeal joint. J. Dairy Sci. 96, 8661457876. 
1458 Orr, W.C., Shadid, G., Harnish, M.J., Elsenbruch, S., 1997. Meal composition and its effect on postprandial sleepiness. Physiol. Behav.62, 709-712.

1460

1461

1462

1463

1464

1465

1466

1467

1468

1469

1470

1471

1472

1473

1474

1475

1476

1477

1478

1479

1480

1481

1482

Pack, A.I., Galante, R.J., Maislin, G., Cater, J., Metaxas, D., Lu, S., Zhang, L., Von Smith, R., Kay, T., Lian, J., Svenson, K., Peters, L.L., 2007. Novel method for high-throughput phenotyping of sleep in mice. Physiol. Genomics 28, 232-238.

Panksepp, J., 2005. Affective consciousness: Core emotional feelings in animals and humans. Conscious. Cogn. 14, 30-80.

Paquette, D., Prescott, J., 1988. Use of novel objects to enhance environments of captive chimpanzees. Zoo Biol. 7, 15-23.

Paterson, L.M., Nutt, D.J., Wilson, S.J., 2009. NAPSAQ-1: National Patient Sleep Assessment Questionnaire in depression. Int. J. Psychiatry Clin. Pract. 13, 48-58.

Pattyn, N., Neyt, X., Heridericlcx, D., Soetens, E., 2008. Psychophysiological investigation of vigilance decrement: Boredom or cognitive fatigue? Physiol. Behav. 93, 369-378.

Pedersen, G.R., Sondergaard, E., Ladewig, J., 2004. The influence of bedding on the time horses spend recumbent. J. Equine Vet. Sci. 24, 153-158.

Pellow, S., Chopin, P., File, S.E., Briley, M., 1985. Validation of open-closed arm entries in an elevated plus-maze as a measure of anxiety in the rat. J. Neurosci. Methods. 14, 149167.

Pepelko, W.E., Clegg, M.T., 1965. Studies of mating behaviour and some factors influencing the sexual response in the male sheep Ovis aries. Anim. Behav.13, 249-258.

Porsolt, R.D., Bertin, A., Jalfre, M., 1977. Behavioral despair in mice - primary screening-test for antidepressants. Archives Internationales De Pharmacodynamie Et De Therapie 229, 327-336.

Prescott, R.G., 1970. Some behavioural effects of variables which influence general level of activity of rats. Anim. Behav.18, 791-796. 
1483 Pritchard, V.L., Lawrence, J., Butlin, R.K., Krause, J., 2001. Shoal choice in zebrafish, Danio 1484 rerio: the influence of shoal size and activity. Anim. Behav.62, 1085-1088.

1485 Pritchett, L.C., Ulibarri, C., Roberts, M.C., Schneider, R.K., Sellon, D.C., 2003. 1486 Identification of potential physiological and behavioral indicators of postoperative pain in 1487 horses after exploratory celiotomy for colic. Appl. Anim. Behav. Sci. 80, 31-43.

1488 Purves, D., Augustine, G.J., Fitzpatrick, D., Hall, W.C., LaMantia, A.-S., McNamara, J.O., 1489 White, L.E., 2007. Neuroscience Fourth Edition. Sinauer Associates, Inc., Sunderland, $1490 \quad$ USA.

1491 Raabymagle, P., Ladewig, J., 2006. Lying behavior in horses in relation to box size. J. Equine 1492 Vet. Sci. 26, 11-17.

1493 Riber, A.B., Forkman, B., 2007. A note on the behaviour of the chicken that receives feather 1494 pecks. Appl. Anim. Behav. Sci. 108, 337-341.

1495 Richmond, M.A., Murphy, C.A., Pouzet, B., Schmid, P., Rawlins, J.N.P., Feldon, J., 1998. A 1496 computer controlled analysis of freezing behaviour. J. Neurosci. Methods. 86, 91-99.

1497 Richter, C.P.A., 1922. A behavioristic study of the activity of the rat. Comp. Psychol. 1498 Monogr. 1, 1-55.

1499 Rochlitz, I., Podberscek, A.L., Broom, D.M., 1998. Welfare of cats in a quarantine cattery. $1500 \quad$ Vet. Rec. 143, 35-39.

1501 Rodgers, R.J., Holch, P., Tallett, A.J., 2010. Behavioural satiety sequence (BSS) Separating 1502 wheat from chaff in the behavioural pharmacology of appetite. Pharmacol. Biochem. 1503 Behav. 97, 3-14.

1504 Rozek, J.C., Danner, L.M., Stucky, P.A., Millam, J.R., 2010. Over-sized pellets naturalize 1505 foraging time of captive Orange-winged Amazon parrots (Amazona amazonica). Appl. 1506 Anim. Behav. Sci. 125, 80-87. 
1507 Rucker, D.D., Petty, R.E., 2004. Emotion specificity and consumer behavior: Anger, sadness, 1508 and preference for activity. Motiv. Emot. 28, 3-21.

1509 Rushen, J., 1991. Problems associated with the interpretation of physiological data in the $1510 \quad$ assessment of animal-welfare. Appl. Anim. Behav. Sci. 28, 381-386.

1511 Rushen, J., Munksgaard, L., Marnet, P.G., DePassille, A.M., 2001. Human contact and the 1512 effects of acute stress on cows at milking. Appl. Anim. Behav. Sci. 73, 1-14.

Russell, J.A., Barrett, L.F., 1999. Core Affect, Prototypical Emotional Episodes, and Other Things Called Emotion : Dissecting the Elephant. J. Pers. Soc. Psychol. 76, 805-819.

Sam, A.H., Troke, R.C., Tan, T.M., Bewick, G.A., 2012. The role of the gut/brain axis in 1516 modulating food intake. Neuropharmacology 63, 46-56.

Samuels, D.J., Samuels, M., 1974. Low Self- Concept As A Cause of Drug Abuse. J. Drug 1518 Educ. 4, 421-436.

Santos, J.M., Gargaro, A.C., Oliveira, A.R., Masson, S., Brandao, M.L., 2005. Pharmacological dissociation of moderate and high contextual fear as assessed by freezing behavior and fear-potentiated startle. Eur. Neuropsychopharmacol. 15, 239-246.

Sargeant, A.B., Eberhardt, L.E., 1975. Death feigning by ducks in response to predation by 1523 2312-2319.

Schirmann, K., Chapinal, N., Weary, D.M., Heuwieser, W., von Keyserlingk, M.A.G., 2012.

1530 Rumination and its relationship to feeding and lying behavior in Holstein dairy cows. J. 1531 Dairy Sci. 95, 3212-3217. 
1532 Schradin, C., Krackow, S., Schubert, M., Keller, C., Schradin, B., Pillay, N., 2007. 1533 Regulation of activity in desert-living striped mice: The importance of basking. Ethology $1534 \quad 113,606-614$

1535 Schulz, K.L., Anderson, D.E., Coetzee, J.F., White, B.J., Miesner, M.D., 2011. Effect of 1536 flunixin meglumine on the amelioration of lameness in dairy steers with amphotericin B1537 1538 Seehuus, B., Mendl, M., Keeling, L.J., Blokhuis, H., 2013. Disrupting motivational 1539 sequences in chicks: Are there affective consequences? Appl. Anim. Behav. Sci. 148, 85$1540 \quad 92$

1541 Seime, R.J., Vickers, K.S., 2006. The challenges of treating depression with exercise: From 1542 evidence to practice. Clin. Psychol. Science and Practice 13, 194-197.

1543 Seligman, M.E.P., 1972. Learned Helplessness. Annu. Rev. Med. 23, 407-412.

1544 Shuhama, R., Del-Ben, C.M., Loureiro, S.R., Graeff, F.G., 2008. Defensive responses to 1545 threat scenarios in Brazilians reproduce the pattern of Hawaiian Americans and non1546 human mammals. Braz. J. Med. Biol. Res. 41, 324-332.

Siegrist, J., 2008. Chronic psychosocial stress at work and risk of depression: evidence from 1548

Stacher, G., Steinringer, H., Schmierer, G., Schneider, C., Winklehner, S., 1982. 1553 Cholecystokinin octapeptide decreases intake of solid food in man. Peptides 3, 133-136.

1554 Steenbergen, P.J., Bardine, N., 2014. Antinociceptive effects of buprenorphine in zebrafish 1555 larvae: An alternative for rodent models to study pain and nociception? Appl. Anim. 1556 Behav. Sci. 152, 92-99. 
1557 Stevenson, M.F., 1983. The captive environment: its effect on exploratory and related 1558 behavioural responses in wild animals, in: Archer, J., Birke, L.I.A. (Eds.), Exploration in 1559 Animals and Man, Van Nostrand Reinhold, London, UK, pp. 176-197.

1560 Strekalova, T., Spanagel, R., Bartsch, D., Henn, F.A., Gass, P., 2004. Stress-induced 1561 anhedonia in mice is associated with deficits in forced swimming and exploration. $1562 \quad$ Neuropsychopharmacology 29, 2007-2017.

1563 Suomi, S.J., Eisele, C.D., Grady, S.A., Harlow, H.F., 1975. Depressive behavior in adult 1564 monkeys following separation from family environment. J. Abnorm. Psychol. 84, 5761565578.

1566 Tait, R.C., Chibnall, J.T., Krause, S., 1990. The pain disability index: psychometric 1567 properties. Pain 40, 171-182.

1568 Taylor, L., Cohen, S., 1972. Psychological Survival: the Experience of Long Term 1569 Imprisonment. Penguin Books Ltd, Harmondsworth, USA.

1570 Temeles, E.J., 1989. Effect of prey consumption on foraging activity of northern harriers. $1571 \quad$ Auk. 106, 353-366.

1572 Thompson, R.K.R., Foltin, R.W., Boylan, R.J., Sweet, A., Graves, C.A., Lowitz, C.E., 1981. 1573 Tonic immobility in Japanese quail can reduce the probability of sustained attack by cats. 1574 Anim. Learn. Behav. 9, 145-149.

1575 Tilly, S.L.C., Dallaire, J., Mason, G.J., 2010. Middle-aged mice with enrichment-resistant 1576 stereotypic behaviour show reduced motivation for enrichment. Anim. Behav.80, 363-373. 1577 Tripaldi, C., De Rosa, G., Grasso, F., Terzano, G.M., Napolitano, F., 2004. Housing system 1578 and welfare of buffalo (Bubalus bubalis) cows. Anim. Sci. 78, 477-483.

1579 Twenge, J.M., Catanese, K.R., Baumeister, R.F., 2003. Social exclusion and the 1580 deconstructed state: Time perception, meaninglessness, lethargy, lack of emotion, and 1581 self-awareness. J. Pers. Soc. Psychol. 85, 409-423. 
van den Bos, R., Meijer, M.K., van Renselaar, J.P., van der Harst, J.E., Spruijt, B.M., 2003.

1583 Anticipation is differently expressed in rats (Rattus norvegicus) and domestic cats (Felis

1584 silvestris catus) in the same Pavlovian conditioning paradigm. Behav. Brain Res. 141, 83158589.

1586 Van Reenen, C.G., O'Connell, N.E., Van der Werf, J.T.N., Korte, S.M., Hopster, H., Jones, 1587 R.B., Blokhuis, H.J., 2005. Responses of calves to acute stress: Individual consistency and 1588 relations between behavioral and physiological measures. Physiol. Behav.85, 557-570.

1589 Veissier, I., Boissy, A., Desire, L., Greiveldinger, L., 2009. Animals' emotions: studies in 1590 sheep using appraisal theories. Anim. Welf. 18, 347-354.

1591 Veissier, I., Després, A.M., Charpentier, G., Ramirez De La Fe, J., De Passillé, I., Rushen, 1592 A.R., Pradel, P., Ramirez De La Fe, P., 2002. Does nutritive and non- nutritive sucking 1593 reduce other oral behaviors and stimulate rest in calves? J. Anim. Sci. 80, 2574-2587.

1594 Vela-Bueno, A., Fernandez-Mendoza, J., Olavarrieta-Bernardino, S., Vgontzas, A.N., Bixler, E.O., de la Cruz-Troca, J.J., Rodriguez-Munoz, A., Olivan-Palacios, J., 2008. Sleep and behavioral correlates of napping among young adults: A survey of first-year university students in Madrid, Spain. J. Am. Coll. Health. 57, 150-158.

1598 Verleye, M., Gillardin, J.M., 2004. Effects of etifoxine on stress-induced hyperthermia, 1599 freezing behavior and colonic motor activation in rats. Physiol. Behav.82, 891-897.

1600 Vieira, A.D., Guesdon, V., De Passille, A.M., von Keyserlingk, M.A.G., Weary, D.M., 2008. 1601 Behavioural indicators of hunger in dairy calves. Appl. Anim. Behav. Sci. 109, 180-189.

1602 Vinke, C.M., van Leeuwen, J., Spruijt, B., 2005. Juvenile farmed mink (Mustela vison) with 1603 additional access to swimming water play more frequently than animals housed with a 1604 cylinder and platform, but without swimming water. Anim. Welf. 14, 53-60.

1605 Volchan, E., Souza, G.G., Franklin, C.M., Norte, C.E., Rocha-Rego, V., Oliveira, J.M., 1606 David, I.A., Mendlowicz, M.V., Coutinho, E.S.F., Fiszman, A., Berger, W., Marques- 
1607 Portella, C., Figueira, I., 2011. Is there tonic immobility in humans? Biological evidence 1608 from victims of traumatic stress. Biol. Psychol. 88, 13-19.

1609 Wagnon, K.A., 1963. Behavior of beef cows on a California range. California Agricultural 1610 Experiment Station Bulletin 799, 60.

1611 Wallace, K.J., Rosen, J.B., 2000. Predator odor as an unconditioned fear stimulus in rats: 1612 Elicitation of freezing by trimethylthiazoline, a component of fox feces. Behav. Neurosci. $1613 \quad 114,912-922$.

1614 Waring, G., 2003. Horse Behavior, second edition. Noyes Publications/William Andrew 1615 Publishing, Norwich, New York.

1616 Weeks, C.A., Danbury, T.D., Davies, H.C., Hunt, P., Kestin, S.C., 2000. The behaviour of 1617 broiler chickens and its modification by lameness. Appl. Anim. Behav. Sci. 67, 111-125.

1618 Weiner, M.F., Lovitt, R., 1979. Conservation-withdrawal versus depression. Gen. Hosp. 1619 Psychiatry. 1(4), 347-349.

1620 Weinger, M.B., Ancoli-Israel, S., 2002. Sleep deprivation and clinical performance. Jama$1621 \quad$ JAMA $287,955-957$.

1622 Wells, D.L., 2004. A review of environmental enrichment for kennelled dogs, Canis 1623 familiaris. Appl. Anim. Behav. Sci. 85, 307-317.

1624 Wells, D.L., 2005. A note on the influence of visitors on the behaviour and welfare of zoo1625 housed gorillas. Appl. Anim. Behav. Sci. 93, 13-17.

1626 Wemelsfelder, F., 1990. Boredom and Laboratory Animal Welfare, in: Rollin, B.E., Kesel, 1627 M.L. (Eds.), The Experimental Animal in Biomedical Research, CRC-Press, Boca Raton, $1628 \quad$ Florida, pp. 243-272.

1629 Werhahn, H., Hessel, E.F., Bachhausen, I., Van den Weghe, H.F.A., 2010. Effects of 1630 Different Bedding Materials on the Behavior of Horses Housed in Single Stalls. J. Equine 1631 Vet. Sci. 30, 425-431. 
1632 Whishaw, I.Q., Flannigan, K.P., Schallert, T., 1982. An assessment of the state hypothesis of 1633 animal 'hypnosis' through an analysis of neocortical and hippocampal EEG in 1634 spontaneously immobile and hypnotized rabbits. Electroencephalogr. Clin. Neurophysiol. $1635 \quad 54,365-374$

1636 Wiedenmayer, C.P., Barr, G.A., 2001. Developmental changes in responsivity to threat are 1637 stimulus-specific in rats. Dev. Psychobiol. 39, 1-7.

1638 Wielebnowski, N.C., Fletchall, N., Carlstead, K., Busso, J.M., Brown, J.L., 2002. 1639 Noninvasive assessment of adrenal activity associated with husbandry and behavioral 1640 factors in the North American clouded leopard population. Zoo Biol. 21, 77-98.

1641 Willner, P., McGuirk, J., Phillips, G., Muscat, R., 1990. Behavioral-analysis of the anorectic 1642 effects of fluoxetine and fenfluramine. Psychopharmacology 102, 273-277.

1643 Wise, R.A., 1974. Lateral hypothalamic electrical stimulation: Does it make animals 1644 'hungry'? Brain Res. 67, 187-209.

1645 Wiseman, M.L., Nolan, A.M., Reid, J., Scott, E.M., 2001. Preliminary study on owner1646 reported behaviour changes associated with chronic pain in dogs. Vet. Rec. 149, 423-424.

1647 Woodgush, D.G.M., Beilharz, R.G., 1983. The enrichment of a bare environment for animals 1648 in confined conditions. Appl. Anim. Ethol. 10, 209-217.

1649 World Health Organisation, 1994. International Statistical Classification of Diseases and 1650 Related Health Problems. World Health Organisation, Geneva.

1651 Wurbel, H., Chapman, R., Rutland, C., 1998a. Effect of feed and environmental enrichment 1652 on development of stereotypic wire-gnawing in laboratory mice. Appl. Anim. Behav. Sci. $1653 \quad 60,69-81$.

1654 Wurbel, H., Freire, R., Nicol, C.J., 1998b. Prevention of stereotypic wire-gnawing in 1655 laboratory mice: Effects on behaviour and implications for stereotypy as a coping 1656 response. Behav. Processes 42, 61-72. 
1657 Zammit, G.K., Ackerman, S.H., Shindledecker, R., Fauci, M., Smith, G.P., 1992. 1658 Postprandial sleep and thermogenesis in normal men. Physiol. Behav.52, 251-259.

1659 Zanella, A.J., Broom, D.M., Hunter, J.C., Mendl, M.T., 1996. Brain opioid receptors in 1660 relation to stereotypies, inactivity, and housing in sows. Physiol. Behav.59, 769-775.

1661 Zeidner, L.P., Denenberg, V.H., Thoman, E.B., Weyand, T., 1983. Comparisons of 1662 behavioral, motoric and electrical criteria for assessment of sleep-wake states in the rabbit. 1663 Physiol. Behav.31, 273-278.

1664 Zonderland, J.J., de Leeuw, J.A., Nolten, C., Spoolder, H.A.M., 2004. Assessing long-term 1665 behavioural effects of feeding motivation in group-housed pregnant sows; what, when and 1666 how to observe. Appl. Anim. Behav. Sci. 87, 15-30.

1667

1668 